\title{
LOAD-CARRYING CAPACITY OF SINGLE-ROW STEEL SCAFFOLDS WITH VARIOUS SETUPS
}

\author{
Jui-Lin Peng ${ }^{1, *}$, Chung-Ming $\mathrm{Ho}^{2}$, Chen-Chung $\operatorname{Lin}^{3}$ and Wai-Fah Chen ${ }^{4}$ \\ ${ }^{1}$ Professor, Department of Construction Engineering, \\ National Yunlin University of Science and Technology, Yunlin, Taiwan, China. \\ ${ }^{2}$ Ph.D. Student, Graduate School of Engineering Science and Technology, \\ National Yunlin University of Science and Technology, Yunlin, Taiwan, China. \\ ${ }^{3}$ Associate Researcher, Institute of Occupational Safety and Health, Council of Labor Affairs, \\ Executive Yuan, Taiwan, China. \\ ${ }^{4}$ Professor, Department of Civil and Environmental Engineering, University of Hawaii at Manoa, Hawaii, USA. \\ *(Corresponding author: E-mail: peng.jl@msa.hinet.net) \\ Received: 19 February 2014; Revised: 16 May 2014; Accepted: 30 June 2014
}

\begin{abstract}
Factors such as high headroom and large spans explain why some areas of a reinforced concrete building, including the entrance lobby of a hospital or the stage area of an auditorium, often require large-scale isolated reinforced concrete beams to support the weight passed down from the slab. On a construction site, single-row steel scaffolds are often set up underneath these isolated beams to function as falsework. The setup method of these steel scaffolds is unique and design-related information is lacking. Single-row steel scaffolds are often set up on a construction site based on the construction experience of workers, explaining the occasional collapses of steel scaffolds underneath the isolated beams. Therefore, this study closely examine why single-row steel scaffolds collapse. Experimental results indicate that treating the variation of headroom under the isolated beams involves using single-row steel scaffolds with different setups. The load-carrying capacities of one-bay, two-story door-type steel scaffolds (2D) closely resemble those of one-bay, three-story door-type steel scaffolds (3D). When multi-bay setups are used, the load-carrying capacities of two-story door-type steel scaffolds (2D) increase with the number of bays. Similarly, when multi-bay setups are used, the load-carrying capacities of one-door, one-square, two-rectangle steel scaffolds (DS2R) also increase with the number of bays. Although the height of the DS2R setup exceeds that of the 2D setup, the load-carrying capacity of the DS2R setup is still higher than that of the 2D setup. This finding demonstrates that structural stiffness of the combined setup of steel scaffolds is higher than that of two-story door-type steel scaffolds. A more convenient design of the strength of steel scaffolds is possible by quickly estimating the load-carrying capacity of a single-row, multi-set steel scaffolds based on that of single-row, one-set steel scaffolds. By applying the second loading, this study also simulates the load-carrying capacity of the steel scaffolds using reusable materials in the worst condition in order to obtain the strength reduction factors of the reusable steel scaffolds. When designing the strength of single-row reusable steel scaffolds, designers may select proper strength reduction factors with different standard deviations based on project fund and safety requirements. Moreover, steel scaffolds with defects randomly selected from the construction site are evaluated. Test results indicate that the load-carrying capacities of the steel scaffolds with defects exceed those of the reusable steel scaffolds in the worst condition. This finding suggests that the strength of the steel scaffolds with defects is still reusable. The vertical displacements of various setups of steel scaffolds under maximum load provide a valuable reference for contractors in designing the isolated reinforced concrete beams when construction accuracy must be considered. The results of this study significantly contribute to efforts to determine related parameters in follow-up numerical analyses in the future.
\end{abstract}

Keywords: Load-carrying capacity, Scaffold, Single-row setup, Steel scaffold

\section{INTRODUCTION}

Owing to the internal layout of a building, large-scale reinforced concrete beams are often designed to bear the load from the top of the structure. Notable examples include beams at the entrance lobby of a hospital or an exhibition hall (Figure 1), beams above the stage area of an auditorium for hanging lighting devices, and beams used in the semi-prefabrication building adopted for building tech-factories or shopping malls that must be completed in a short period of time. Underneath these beams and in a longitudinal direction, contractors often set up single-row steel scaffolds with various setups to support the weight of the fresh concrete within the beams. 


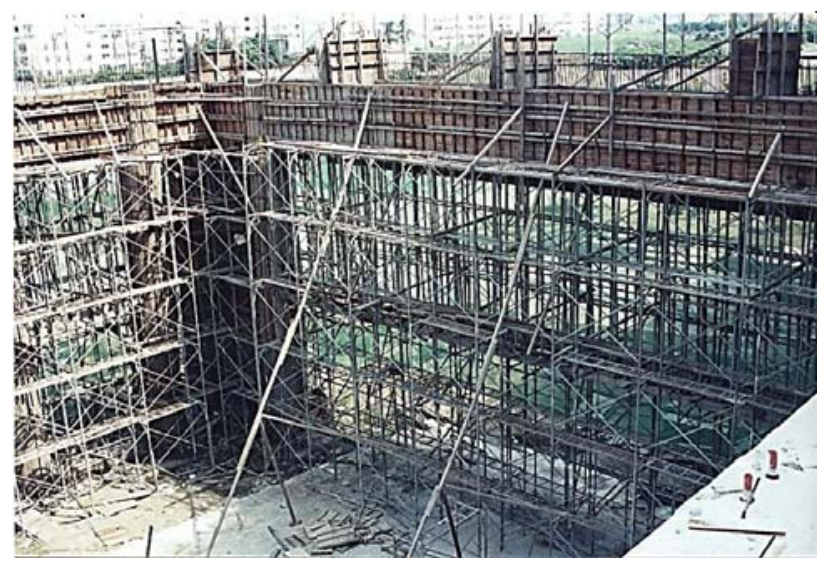

Figure 1. Setup of Single-row Steel Scaffolds Underneath the Beam of the Entrance Lobby of a Hospital during Construction

In a construction project, when steel scaffolds are frequently used as falsework to support the weight of the fresh reinforced concrete of beams and slabs on the construction site, steel scaffolds are usually set up as large-scale multi-row scaffolding systems. The contractor generally connects the multi-row steel scaffolds with horizontal stringers to function as a reinforcement in order to enhance the overall strength of the steel scaffolding structure.

Unlike the above-mentioned multi-row, single-type steel scaffolds reinforced with horizontal stringers, the steel scaffolds underneath an isolated beam are usually arranged as a single-row type of steel scaffolds with various setups. These single-row setups lead to structural behaviors that differ from those of multi-row steel scaffolds. If the designers fail to determine the variation of strength between single-row and multi-row steel scaffolds, the fault may lead to an extremely high collapse risk of the single-row steel scaffolds.

Figure 2 shows the collapse scene of single-row steel scaffolds underneath the beam of the entrance lobby of a new hospital during construction in central Taiwan. Figure 3 shows the collapse scene of single-row steel scaffolds underneath the beam of a shopping mall in a semi-prefabrication construction in central Taiwan. Figure 4 shows the collapse scene of single-row steel scaffolds underneath the beam of the auditorium of a university during construction in central Taiwan. The frequent occurrence of accidents involving the collapse of single-row steel scaffolds warrants an investigation of the load-carrying capacities and failure modes of single-row steel scaffolds.

The structural behaviors of falsework have been extensively studied. In terms of analytical study on steel scaffolds, Zhang and Rasmussen et al. (2010) analyzed the variability of parameters related to steel scaffolds, including joint stiffness, initial geometric imperfection, yield stress, and load eccentricity. That study also obtained the structural strength of the steel scaffolding structures based on Monte Carlo simulation. Zhang and Rasmussen et al. (2012) also investigated the failure modes of steel scaffolds, the effect of different random variables on structural strength and the reliability analysis of scaffolding structures. Chan et al. (2003) conducted nonlinear analyses on the shoring structures that did not assume an effective length. Based on stability functions, while adopting the notional disturbance force and considering the $P-\delta$ and $P-\Delta$ effects, the analytical method accurately estimates the load-carrying capacities of scaffolding structures with nonlinear analyses. Chan and Peng (2000) developed a computer method for stability analysis and design of slender scaffolding systems. The concept of system instability in place of the conventional method checking member buckling in K-factor was utilized. The new method carries a potential widely used by structural engineers for design of scaffolding systems. 


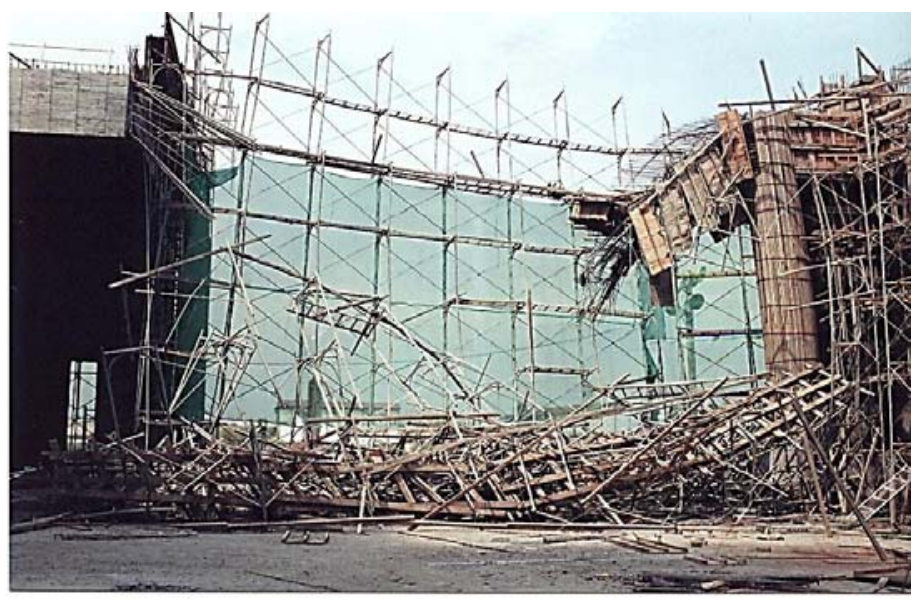

Figure 2. Collapse Scene of Single-row Steel Scaffolds Underneath the Beam of the Entrance Lobby of Chayi Tzu-Chi Hospital during Construction in Chayi County, Taiwan

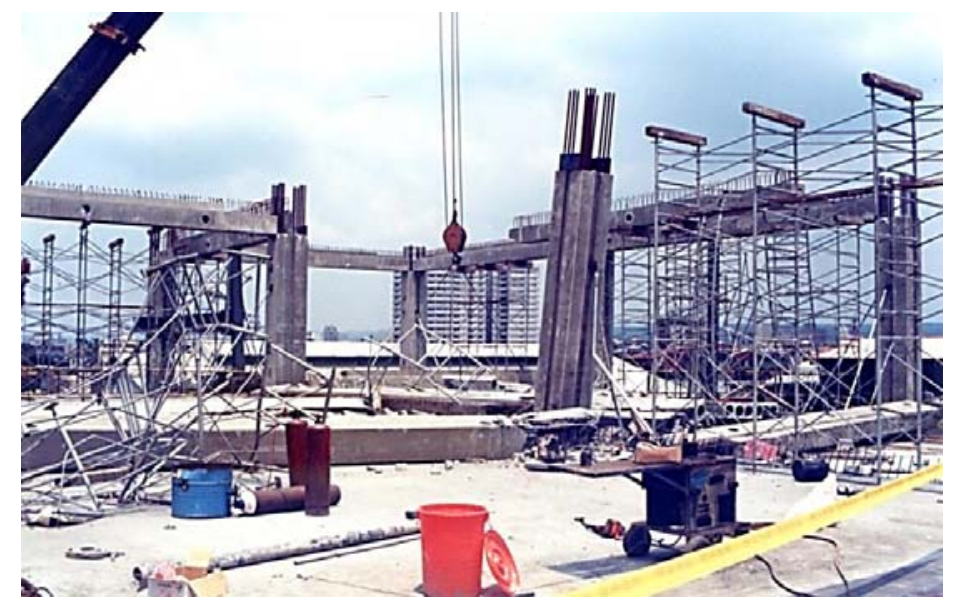

Figure 3. Collapse Scene of Single-row Steel Scaffolds of RT-mart Mall under Semi-prefabrication Construction in Zhanghua County, Taiwan

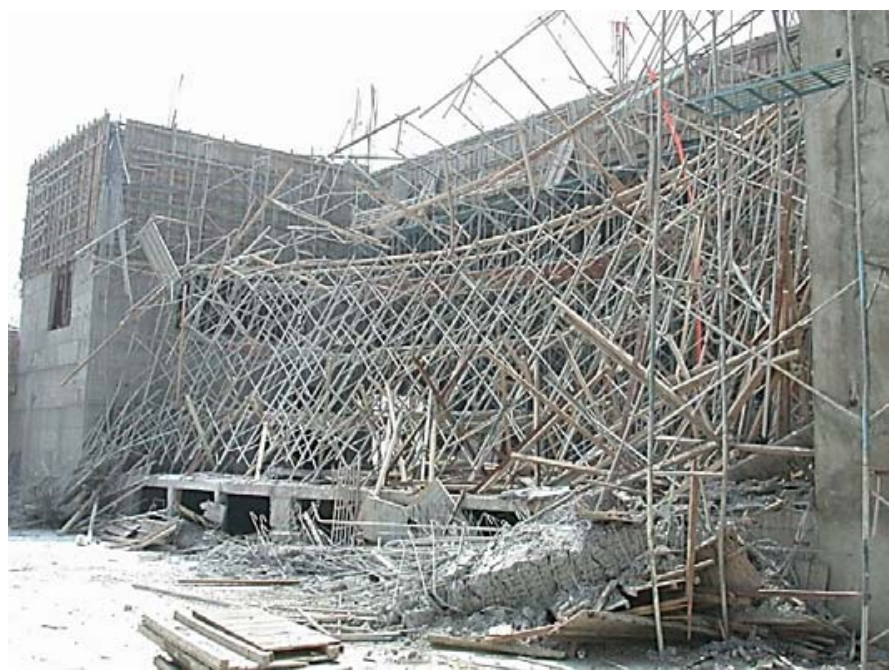

Figure 4. Collapse Scene of Single-row Steel Scaffolds Underneath the Beam of the Auditorium of Mingdao College of Management during Construction in Zhanghua County, Taiwan 
While studying modular frame-type scaffolds, Weesner and Jones (2001) conducted load-carrying capacity tests on four modular frame-type scaffolds. That study also conducted eigenbuckling and geometrically nonlinear analyses of their load-carrying capacities by the analytical program ANSYS. Yu et al. (2004) examined the load-carrying capacities of multi-story modular door-type steel scaffolds through means of nonlinear analyses and loading tests. According to their results, boundary conditions of the U-shaped screw jacks and base screw jacks significantly affect the load-carrying capacity of the scaffolding structures. Huang et al. (2000) simplified the 2-D finite element analysis model of door-type steel scaffolds and, in doing so, obtained a closed-form solution of the simplified model. This closed-form solution is related to the number of stories, material properties, and section properties of the steel scaffolds.

Peng et al. (1996a) developed basic structure models of the "door-type steel scaffold system" and "steel scaffold system with wooden shores". That study also explored the structural behaviors and failure modes of the unit setup of these two structure models with second order analyses. Peng et al. (1996b) examined the structural design guidelines of the "door-type steel scaffold system" and "steel scaffold system with wooden shores". That study also explored the variation of load-carrying capacities and failure modes between these two structural systems. Peng et al. (2010) conducted loading tests on two-story systems with wooden shores or adjustable steel shores based on construction site setups in order to determine why these two-story systems collapse and propose suggestions on how to improve their load-carrying capacities.

Peng et al. (1997) explored how joint stiffnesses, boundary conditions, and initial eccentricities affect the load-carrying capacities of steel scaffolds through second-order elastic analyses with semi-rigid joints. That study also studied the variation of the load-carrying capacities between 2-D and 3-D structural analyses. In addition to developing a simplified analysis model for a steel scaffold system with wooden shores, Peng et al. (1998) obtained an analytical solution of the simplified model based on the stability theory. That study also explored how the leaning column effect influences the load-carrying capacities of steel scaffold systems. That study also established the relationship between first-order analysis and second-order analysis, as well as proposed design steps for the structural design of steel scaffolds.

Peng et al. (2001) developed an approximation method based on exact moment-curvature relations to analyze the strength of the steel tubes of the scaffolds under an axial load. Based on the deduced formula, that study also developed a load-deflection curve, which closely resembled the test results. Importantly, that study are conducive to confirming the quality of factory-fabricated steel scaffold components. Additionally, Peng et al. (2007) explored the load-carrying capacities of different setups of steel scaffold structural systems under different loads. While the setups of steel scaffolds included rectangular, $L$-shaped and $U$-shaped types, the second-order analysis was also performed on different loads, including uniform loads, various geometry-dependent loads, and time-dependent incremental loads.

While studying tube \& coupler scaffolds, Liu et al. (2010a) and Liu et al. (2010b) conducted loading tests and ANSYS numerical analyses on full-size tube \& coupler scaffolds with and without cross-brace respectively. This study explored the load-carrying capacities and failure modes of the tube \& coupler scaffolds with different setups. While studying system scaffolds, Peng et al. (2009) conducted second-order analyses and loading tests on system scaffolds. That study also explored the load-carrying capacities and failure modes of the system scaffolds with different setups and under various situations such as number of stories, joint stiffnesses and boundary conditions. 
Above falsework-related studies focus mainly on various scaffolding structures, including modular frame-type scaffolds, door-type steel scaffolds, tube \& coupler scaffolds, and system scaffolds, with one-bay or multi-row setups. However, single-row steel scaffolds with different setups have seldom been studied. The results of those studies on steel scaffolds can only serve as a reference for estimating the load-carrying capacities of single-row steel scaffolds with various setups. Therefore, investigating the load-carrying capacities and failure modes of single-row steel scaffolds with various setups is of priority concern.

\section{RESEARCH OBJECTIVE AND CONTENTS}

This study explores the structural behaviors of single-row steel scaffolds by conducting loading tests based on various scaffold setups commonly used in construction sites. In addition to providing the dimensions and elastic modulus of the steel scaffolds, test results of this study provide a valuable reference for determining related parameters in follow-up numerical analyses, including the bending moment stiffnesses of scaffold joints, U-shaped screw jacks and base screw jacks. Hopefully, results of this study can facilitate efforts to improve the structural design of single-row steel scaffolds with various setups, ultimately reducing the collapse risks of these scaffolding structures. In particular, this this study focuses on the following objectives:

- determine the load-carrying capacities and failure modes of single-row, one-bay steel scaffolds with various setups to function as the basis for strength comparison;

- determine the load-carrying capacities and failure modes of single-row, multi-bay steel scaffolds with various setups;

- estimate the load-carrying capacities of single-row, multi-set scaffolds based on those of single-row, one-set scaffolds;

- determine the load-carrying capacities and failure modes of steel scaffolds with various setups in the worst quality condition on construction sites;

- determine the difference of load-carrying capacities between the steel scaffolds with defects and those in the worst quality condition on construction sites; and

- determine the vertical displacements of multi-bay steel scaffolds with various setups at failure to facilitate efforts to accurately control beam deformation.

\section{TEST PLANNING}

This study attempts to accurately reflect the conditions on construction sites by using three setups of single-row steel scaffolds: one-bay (i.e., two-set) steel scaffolds, multi-bay steel scaffolds, and one-bay steel scaffolds with defects. Two loadings are applied to each setup of steel scaffolds in the test. The first loading is applied to obtain the load-carrying capacity of each setup of steel scaffolds. After unloading, each setup of steel scaffolds is reset and, then, the load-carrying capacity of the steel scaffolds in the worst condition on the construction site is determined using the second loading.

\subsection{One-bay Steel Scaffolds}

In this study, tests are performed on one-bay steel scaffolds to provide a reference for tests on single-row steel scaffolds. These tests are conducted on various one-bay steel scaffolds with different heights to explore the correlation between the load-carrying capacity and change in the number of stories of steel scaffolds. The steel scaffolds used in the tests consist of a $170.00 \mathrm{~cm}$ high door scaffold (D), $91.30 \mathrm{~cm}$ high square scaffold (S), and $49.00 \mathrm{~cm}$ high rectangle scaffold (R) (Figure. 5). 


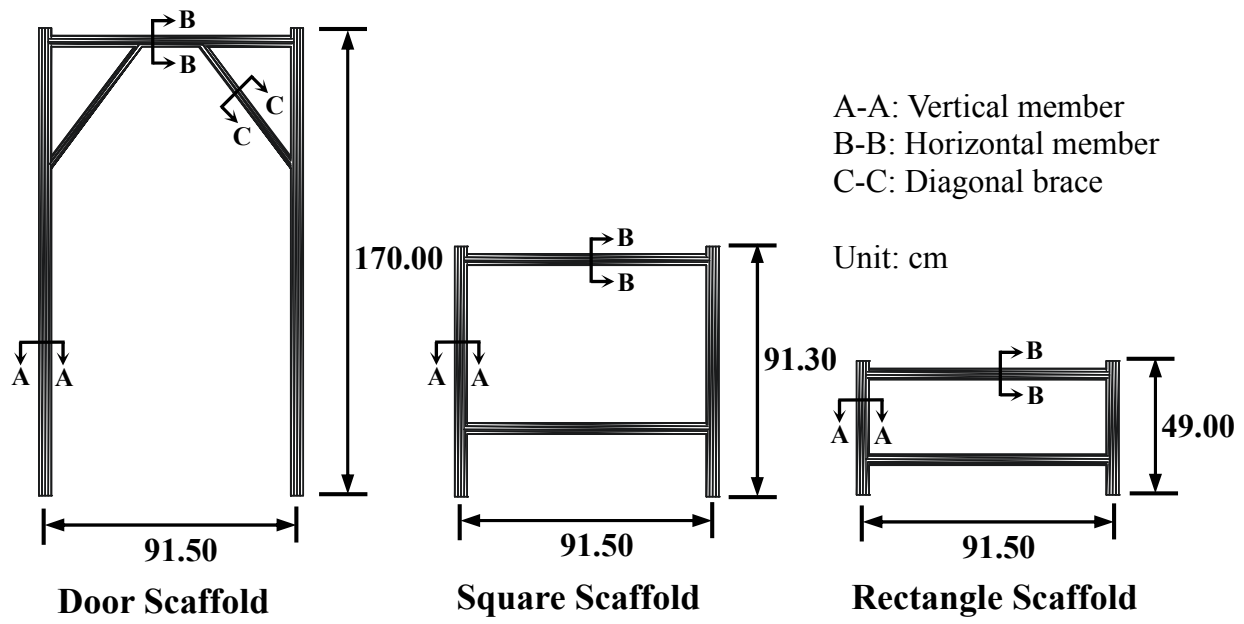

Figure 5. Dimensions of Members of Steel Scaffolds

Tests of one-bay, two-story door-type steel scaffolds (2D) are conducted on a setup consisting of two $170.00 \mathrm{~cm}$ high door-type steel scaffolds. The top and bottom of the scaffolding structure are attached with a $10.00 \mathrm{~cm}$ U-shaped screw jack and a base screw jack, respectively, and the 15.00 $\mathrm{cm}$ I-shaped steels are placed in the U-shaped screw jack. The scaffolding structure is reinforced with cross-brace on both sides of each story, and the total height of the scaffold system is 375.00 $\mathrm{cm}(=15.00+10.00+170.00+170.00+10.00)$. Figure $6(\mathrm{~A})$ shows the setup of the entire scaffold. Unless otherwise specified, the top and bottom arrangements as well as the cross-brace reinforcement for other one-bay steel scaffolds under test are the same. The total height of one-bay, three-story door-type steel scaffolds (3D) is $545.00 \mathrm{~cm}(=15.00+10.00+170.00+$ $170.00+170.00+10.00)$. Also, the setup of the three-story scaffolding structure is similar to that of the two-story door-type steel scaffolds, as shown in Figure 6(B). Figure 6 also shows the xyz coordinates to explain the deformation direction of the steel scaffolds, with $y-z$ plane indicating "the in-plane" and x-z plane indicating "the out-of-plane."

Figure 7(A) shows a combined setup of (bottom-up) one door, one square and one rectangle steel scaffolds (DSR) with a total height of $345.30 \mathrm{~cm}(=15.00+10.00+49.00+91.30+170.00+10.00)$. Figure 7(B) shows a combined setup of (bottom-up) one door, one square and two rectangle steel scaffolds (DS2R) with a total height of $394.30 \mathrm{~cm}(=15.00+10.00+49.00+49.00+91.30+$ $170.00+10.00)$. Figure 7(C) shows a combined setup of (bottom-up) two door, one square and one rectangle steel scaffolds (2DSR) with a total height of $515.30 \mathrm{~cm}(=15.00+10.00+49.00+$ $91.30+170.00+170.00+10.00)$.

\subsection{Multi-bay Steel Scaffolds}

The setups of single-row, multi-bay steel scaffolds differ from each other, depending on the cross-section dimensions and the beam length. For a beam with smaller cross-sections and lengths, the multi-bay steel scaffolds can be set up with larger spans since the beam weight is light. As shown in Figure 8, span of the steel scaffolds is $183.00 \mathrm{~cm}$. For a beam with larger cross-sections and lengths, multi-bay steel scaffolds can be set up with smaller spans and an overlap installation since the beam weight is heavy. As shown in Figure 9, span of the steel scaffolds is reduced to $91.50 \mathrm{~cm}$.

Figures $10(\mathrm{~A})$ to $10(\mathrm{C})$ show the setups of two-story, multi-bay steel scaffold systems with a total height of $375.00 \mathrm{~cm}(=15.00+10.00+170.00+170.00+10.00)$. Figure 10(A) shows the setup of a two-story, two-bay steel scaffold system (2D-2B) with a total length of $366.00 \mathrm{~cm}(183.00 \mathrm{~cm}$ for 
each span) $(=2 \times 183.00)$. The top and bottom of the scaffolding structure are attached with a 10.00 $\mathrm{cm}$ U-shaped screw jack and base screw jack, respectively; in addition, a $15.00 \mathrm{~cm}$ I-beam is placed in the U-shaped screw jack. The scaffolding structure is reinforced with a cross-brace on both sides of each story. A $6.00 \mathrm{~m}$ long, $20.00 \mathrm{~cm}$ high I-shaped steel is attached on the top of the $15.00 \mathrm{~cm}$ I-beams to connect the two-bay scaffolds. Unless otherwise specified, the setup arrangements for other multi-bay steel scaffolds under the test are the same. Figure 10(B) shows the setup of two-story, three-bay steel scaffold system (2D-3B) with a total length of $274.50 \mathrm{~cm}$ $(=3 \times 91.50)(91.50 \mathrm{~cm}$ for each span). Figure $10(\mathrm{C})$ shows the setup of a two-story, four-bay steel scaffold system $(2 \mathrm{D}-4 \mathrm{~B})$ with a total length of $366.00 \mathrm{~cm}(=4 \times 91.50)(91.50 \mathrm{~cm}$ for each span).

Figures 11(A) to 11(C) show the setups of (bottom-up) one-door, one-square, two-rectangle, multi-bay steel scaffold systems with a total height of $394.30 \mathrm{~cm}$ $(=15.00+10.00+49.00+49.00+91.30+170.00+10.00)$. Figure 11(A) shows the setup of a two-bay steel scaffold system (DS2R-2B) with a total length of $366.00 \mathrm{~cm}(=2 \times 183.00)(183.00 \mathrm{~cm}$ for each span). Figure 11(B) shows the setup of a three-bay steel scaffold system (DS2R-3B) with a total length of $274.50 \mathrm{~cm}(=3 \times 91.50)(91.50 \mathrm{~cm}$ for each span). Figure $11(\mathrm{C})$ shows the setup of a four-bay steel scaffold system (DS2R-4B) with a total length of $366.00 \mathrm{~cm}(=4 \times 91.50)(91.50 \mathrm{~cm}$ for each span).

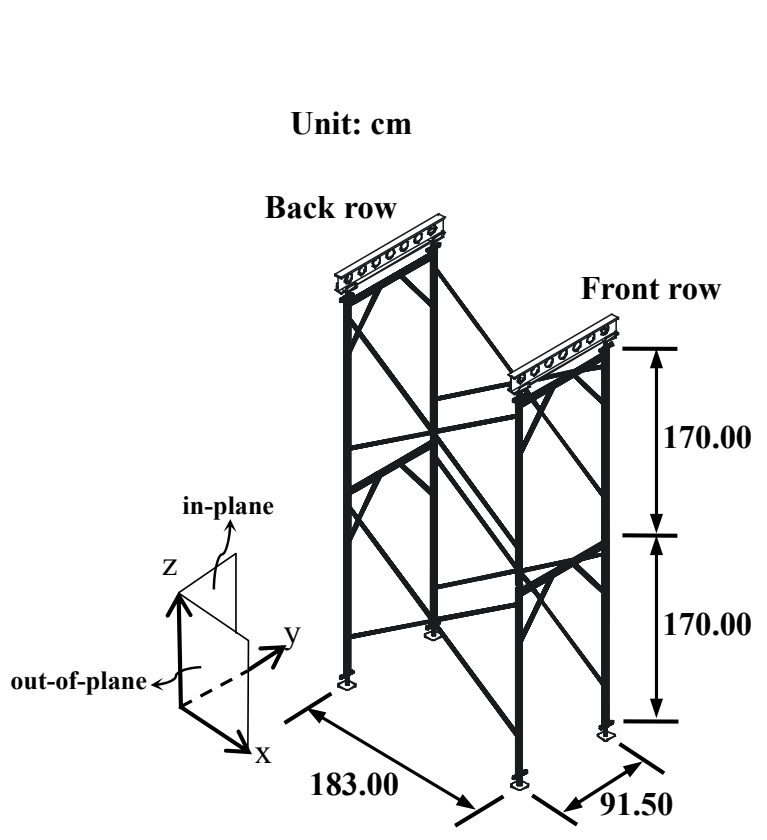

(A) 2D

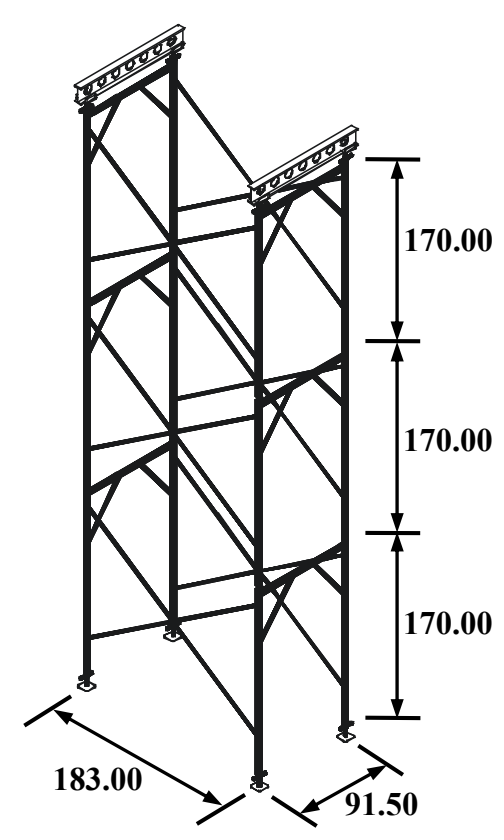

(B) 3D

Figure 6. Setup of One-bay, Two-story Door-type (2D) and Three-story Door-type (3D) Scaffolds 


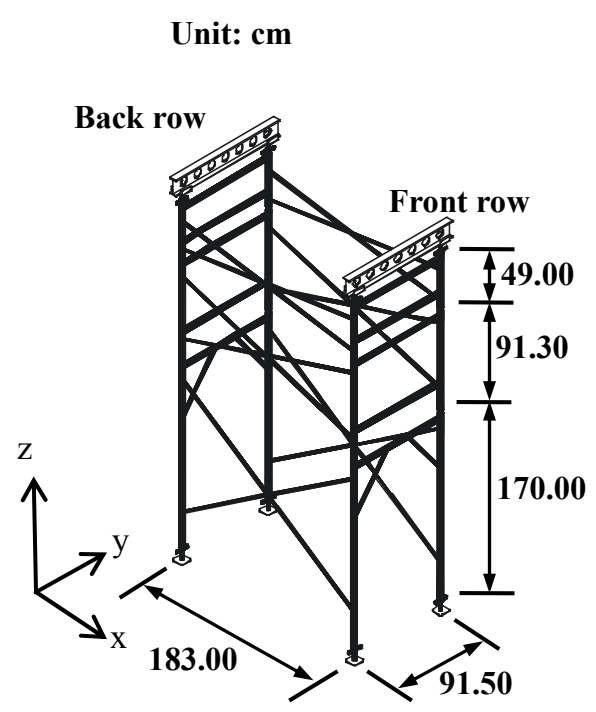

(A) DSR

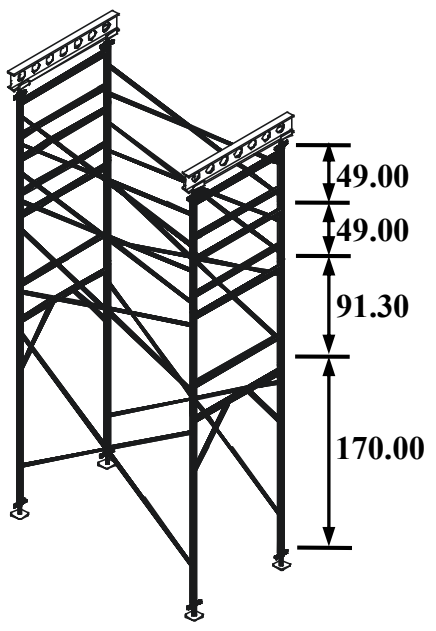

(B) DS2R

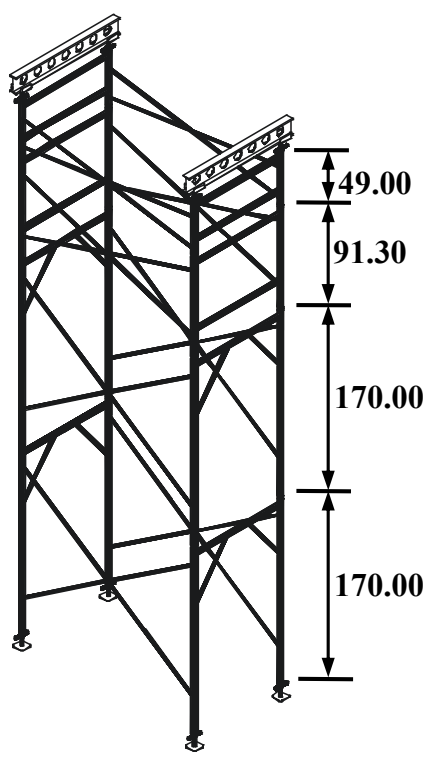

(C) 2DSR

Figure 7. Setup of One-bay DSR, DS2R and 2DSR Scaffolds

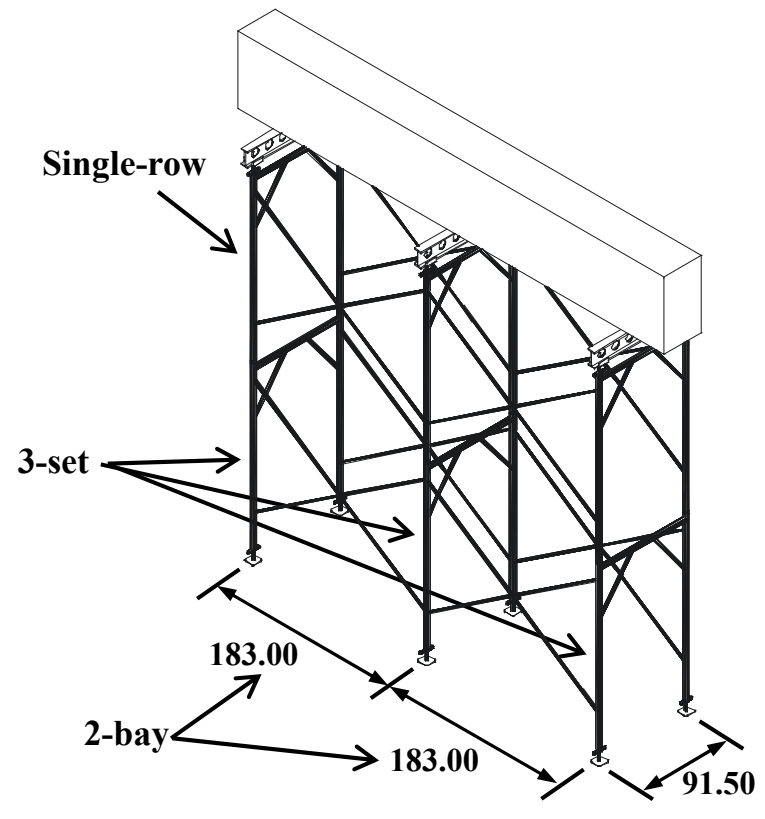

Perspective View

Unit: $\mathbf{c m}$

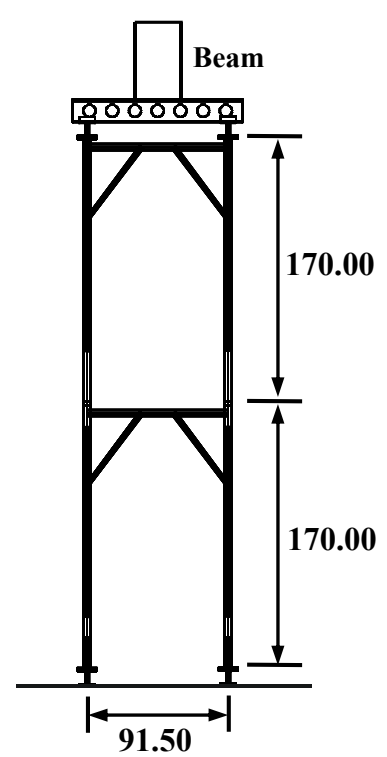

Front View

(Single-row, 2-bay setup)

Figure 8. Setup of Scaffold System with Larger Spans under a Smaller Beam 


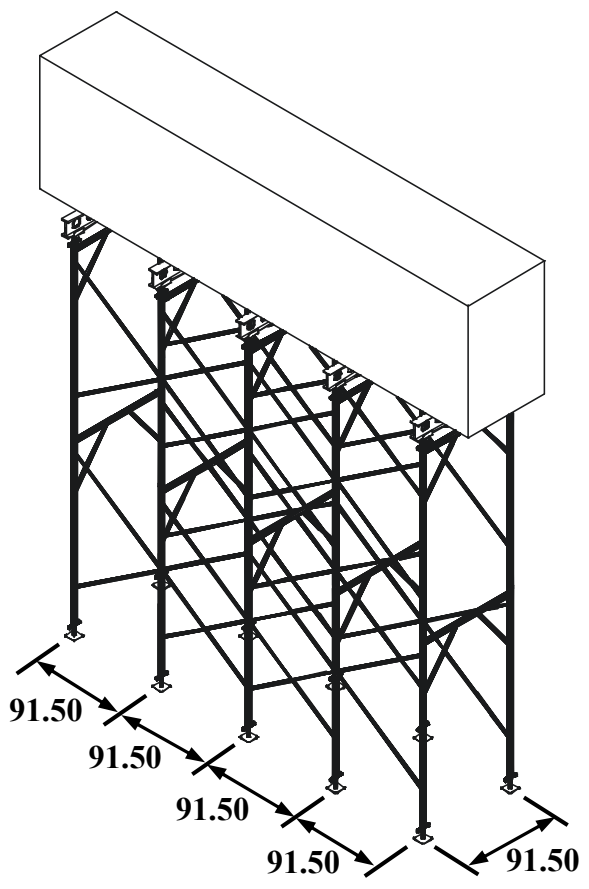

Perspective View

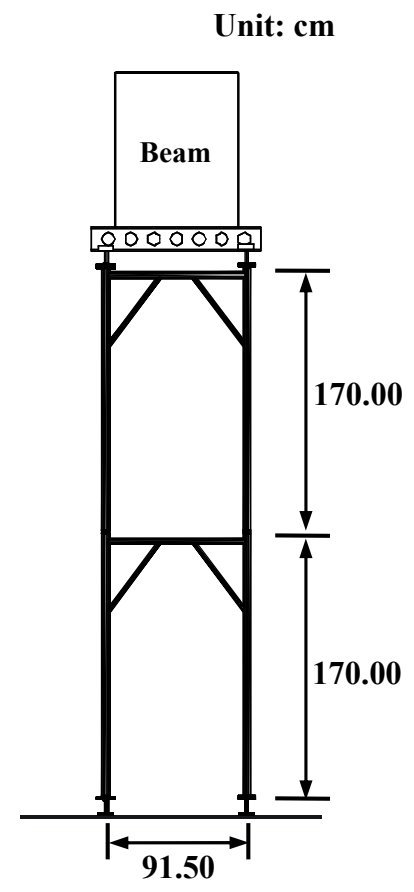

Front View

(Single-row, interlaced 4-bay setup)

Figure 9. Setup of Scaffold System with Smaller Spans under a Larger Beam

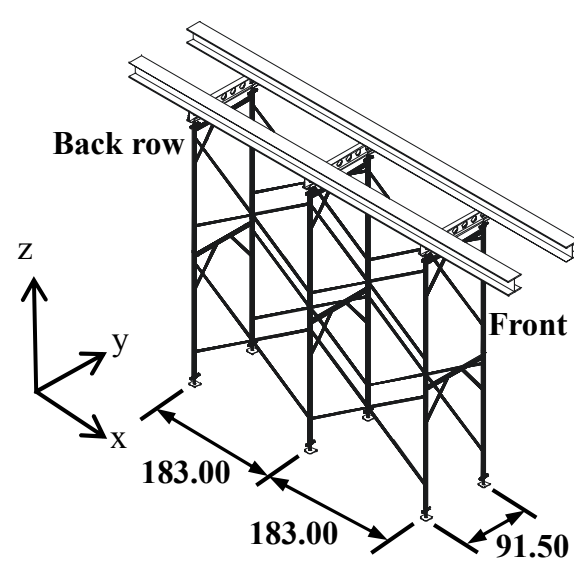

(A) 2D-2B

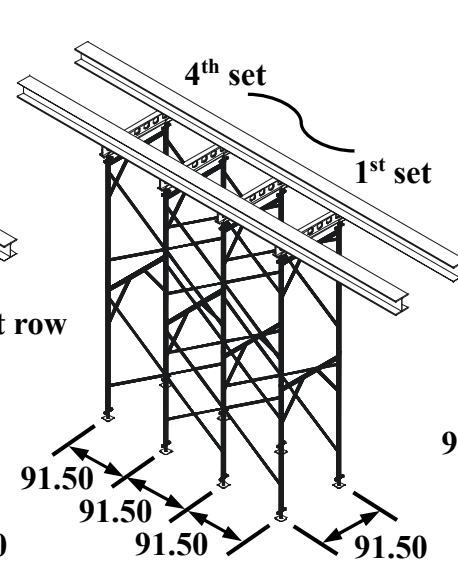

(B) 2D-3B

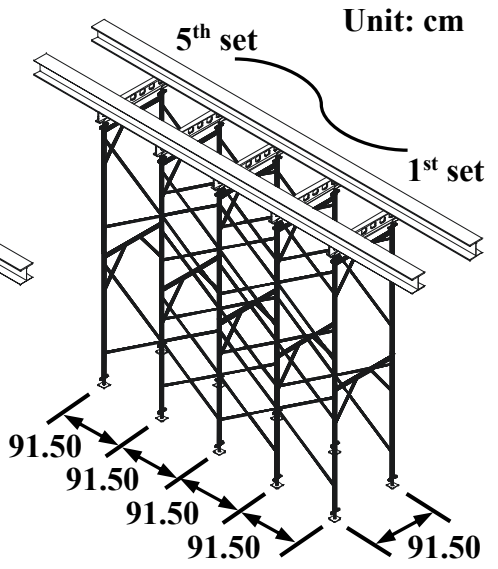

(C) 2D-4B

Figure 10. Setup of 2D-2B, 2D-3B, and 2D-4B scaffold systems 


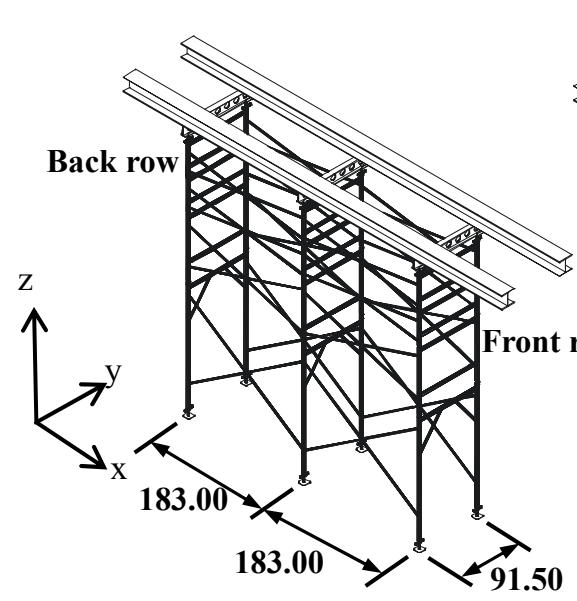

(A) DS2R-2B

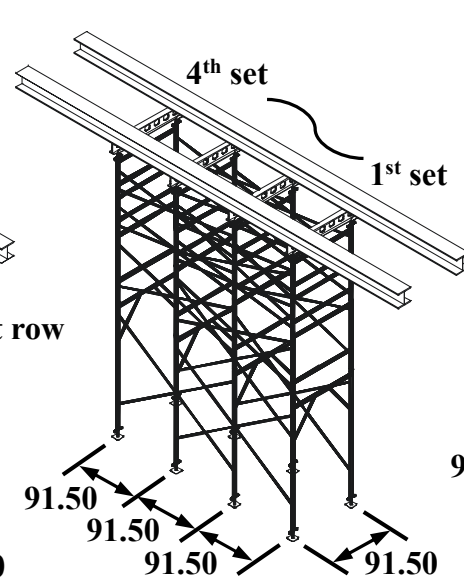

(B) DS2R-3B

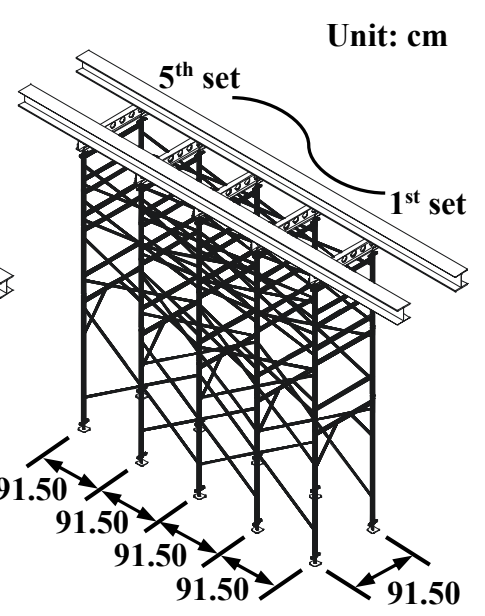

(C) DS2R-4B

Figure 11. Setup of DS2R-2B, DS2R-3B and DS2R-4B Scaffold Systems

\subsection{One-bay Steel Scaffolds with Defects}

Steel scaffolds are often reused as temporary structures on a construction site. After construction, the contractor eliminates the seriously damaged steel scaffolds by examining them and refilling new ones for the next construction project. Steel scaffolds used on a construction site are generally set up with new and old materials. Since collision of steel scaffolds is unavoidable during construction, repeatedly used steel scaffolds tend to have deformations or indentations.

This study explores the effect of these deformations or indentations on the load-carrying capacities of steel scaffolding structures. The setups for the tests are the same as those shown in Figures 6(A), 6(B), 7(A) and 7(B). These test results can be compared with those on steel scaffolds without defects to determine how defects affect the load-carrying capacities of the steel scaffolds.

\section{DIMENSIONS AND MATERIAL PROPERTIES}

Section A-A of Figure 5 shows the vertical main tube of the steel scaffolds with $D$ (external diameter) $=48.26 \pm 0.30 \mathrm{~mm}$ and $t$ (thickness) $=2.39 \pm 0.10 \mathrm{~mm}$. Section B-B shows the horizontal bar of the steel scaffolds with $D$ (external diameter) $=42.06 \pm 0.30 \mathrm{~mm}$ and $t$ (thickness) $=2.10 \pm 0.10 \mathrm{~mm}$. Section C-C shows the diagonal bar of the steel scaffolds with $D$ (external diameter) $=26.89 \pm 0.30 \mathrm{~mm}$ and $t$ (thickness) $=1.65 \pm 0.10 \mathrm{~mm}$. Additionally, the cross-brace used in the combined setup has an external diameter of $21.27 \pm 0.30 \mathrm{~mm}(D)$ and a thickness of $1.59 \pm 0.10 \mathrm{~mm}(t)$.

The elastic moduli of the material are obtained from tests on three randomly selected steel scaffolds. Test results of the three steel scaffolds are $186.62 \mathrm{kN} / \mathrm{mm}^{2}, 190.48 \mathrm{kN} / \mathrm{mm}^{2}$, and $183.52 \mathrm{kN} / \mathrm{mm}^{2}$, respectively. Mean value of the three elastic moduli is $186.87 \mathrm{kN} / \mathrm{mm}^{2}$, which is close to the nominal value of $200.12 \mathrm{kN} / \mathrm{mm}^{2}$. 


\section{RESULTS AND DISCUSSION}

\subsection{One-bay Steel Scaffolds}

Based on commonly used setups of one-bay steel scaffolds on a construction site, tests are conducted on five setups of one-bay steel scaffolds: two-story door-type scaffolds (2D), three-story door-type scaffolds (3D), combined setup of one-door, one-square, one-rectangle scaffolds (DSR), combined setup of one-door, one-square, two-rectangle scaffolds (DS2R), and combined setup of two-door, one-square, one-rectangle scaffolds (2DSR).

Two tests (A and B) are performed for each setup of one-bay steel scaffold applied by two loadings. Test results of one-bay steel scaffolds indicate that the failure modes of the five setups of steel scaffolds in both loadings are similar. The vertical displacements of all five setups of steel scaffolds under maximum load are less than $12.74 \mathrm{~mm}$. Table 1 summarizes all of the test results.

Table 1. Test Results of One-bay Steel Scaffolds

\begin{tabular}{|c|c|c|c|c|c|c|c|}
\hline \multirow{2}{*}{\multicolumn{2}{|c|}{$\begin{array}{l}\text { Setup } \\
\text { type }\end{array}$}} & \multirow{2}{*}{ Figure } & \multirow{2}{*}{$\begin{array}{l}\text { Height } \\
(\mathrm{cm})\end{array}$} & \multirow{2}{*}{$\begin{array}{c}\text { Load, } \\
\text { Displacement }\end{array}$} & \multicolumn{3}{|c|}{ Test value $(\mathrm{kN})$; Displacement $(\mathrm{mm})$} \\
\hline & & & & & Test A & Test B & Average \\
\hline \multirow{10}{*}{ 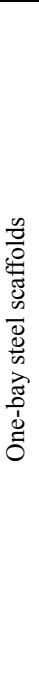 } & \multirow{2}{*}{ 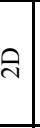 } & \multirow{2}{*}{ H } & \multirow{2}{*}{375.00} & $\begin{array}{c}2 \mathrm{D} \\
(2 \mathrm{DT})\end{array}$ & $\begin{array}{c}200.94 \\
(141.15) \\
\end{array}$ & $\begin{array}{c}199.76 \\
(160.32) \\
\end{array}$ & $\begin{array}{c}200.35 \\
(150.74) \\
\end{array}$ \\
\hline & & & & Displacement & $\begin{array}{c}8.30 \\
(7.73) \\
\end{array}$ & $\begin{array}{c}8.59 \\
(10.11) \\
\end{array}$ & $\begin{array}{c}8.45 \\
(8.92) \\
\end{array}$ \\
\hline & \multirow{2}{*}{ लि } & & \multirow{2}{*}{545.00} & $\begin{array}{c}3 \mathrm{D} \\
(3 \mathrm{DT})\end{array}$ & $\begin{array}{c}201.68 \\
(114.65)\end{array}$ & $\begin{array}{c}197.49 \\
(141.92)\end{array}$ & $\begin{array}{c}199.59 \\
(128.29)\end{array}$ \\
\hline & & & & Displacement & $\begin{array}{c}11.68 \\
(10.02)\end{array}$ & $\begin{array}{c}11.84 \\
(10.73)\end{array}$ & $\begin{array}{c}11.76 \\
(10.38)\end{array}$ \\
\hline & \multirow{2}{*}{\begin{tabular}{l}
\multicolumn{1}{c}{} \\
$\tilde{a}$ \\
0
\end{tabular}} & \multirow[t]{2}{*}{ 只 } & \multirow{2}{*}{345.30} & $\begin{array}{c}\text { DSR } \\
\text { (DSRT) }\end{array}$ & $\begin{array}{c}280.91 \\
(151.57)\end{array}$ & $\begin{array}{c}287.64 \\
(148.62)\end{array}$ & $\begin{array}{c}284.28 \\
(150.10)\end{array}$ \\
\hline & & & & Displacement & $\begin{array}{l}11.18 \\
(8.13)\end{array}$ & $\begin{array}{l}11.43 \\
(7.78)\end{array}$ & $\begin{array}{l}11.31 \\
(7.96)\end{array}$ \\
\hline & \multirow{2}{*}{ 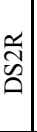 } & \multirow[t]{2}{*}{ 目 } & \multirow{2}{*}{394.30} & $\begin{array}{c}\text { DS2R } \\
(\mathrm{DS} 2 \mathrm{RT})\end{array}$ & $\begin{array}{c}287.58 \\
(137.25)\end{array}$ & $\begin{array}{c}282.58 \\
(132.38)\end{array}$ & $\begin{array}{c}285.08 \\
(134.82)\end{array}$ \\
\hline & & & & Displacement & $\begin{array}{l}12.30 \\
(9.27)\end{array}$ & $\begin{array}{l}11.44 \\
(8.34)\end{array}$ & $\begin{array}{l}11.87 \\
(8.81)\end{array}$ \\
\hline & \multirow{2}{*}{$\begin{array}{c}\underline{w} \\
\stackrel{2}{2}\end{array}$} & \multirow[t]{2}{*}{ 同 } & \multirow{2}{*}{515.30} & $\begin{array}{c}\text { 2DSR } \\
\text { (2DSRT) }\end{array}$ & $\begin{array}{l}237.86 \\
(96.50)\end{array}$ & $\begin{array}{c}240.97 \\
(109.44)\end{array}$ & $\begin{array}{c}239.42 \\
(102.97)\end{array}$ \\
\hline & & & & Displacement & $\begin{array}{c}11.34 \\
(11.50)\end{array}$ & $\begin{array}{c}12.74 \\
(11.38)\end{array}$ & $\begin{array}{c}12.04 \\
(11.44)\end{array}$ \\
\hline & & & & & & old & \\
\hline
\end{tabular}

\subsubsection{Two-story door-type setup (2D)}

Average maximum load of the first loadings is $200.35 \mathrm{kN}$ and that of the second loadings is 150.74 $\mathrm{kN}$, which is $75 \%(=150.74 / 200.35)$ of that of the first loadings. Figure 12 shows the loads and vertical displacements of test A of one-bay, two-story door-type steel scaffolds (2D) under first loading and second loading, respectively. Figure 13(A) shows the failure modes of one-bay, two-story door-type steel scaffolds. According to figure 13(A), deformation occurs mainly on the in-plane of the back row at failure.

\subsubsection{Three-story door-type setup (3D)}

Average maximum load of the first loadings is $199.59 \mathrm{kN}$ and that of the second loadings is 128.29 $\mathrm{kN}$, which is $64 \%(=128.29 / 199.59)$ of that of the first loadings. Figure 13(B) shows the failure modes of the one-bay, three-story door-type steel scaffolds. According to this figure, the 
deformation occurs mainly on the in-plane of the back row at failure. Maximum load of the one-bay, three-story door-type steel scaffolds (3D) closely resembles that of the one-bay, two-story door-type steel scaffolds (2D). This finding suggests that the effect of height (2D or 3D) on the load-carrying capacities of door-type steel scaffolds is negligible.

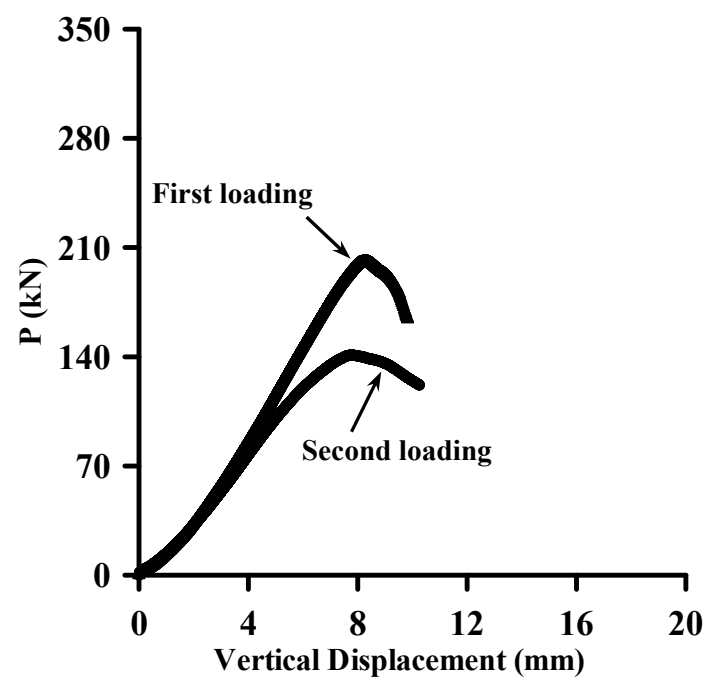

Figure 12. Loads and Vertical Displacements of One-bay, Two-story Door-type Steel Scaffolds (2D) in Test A

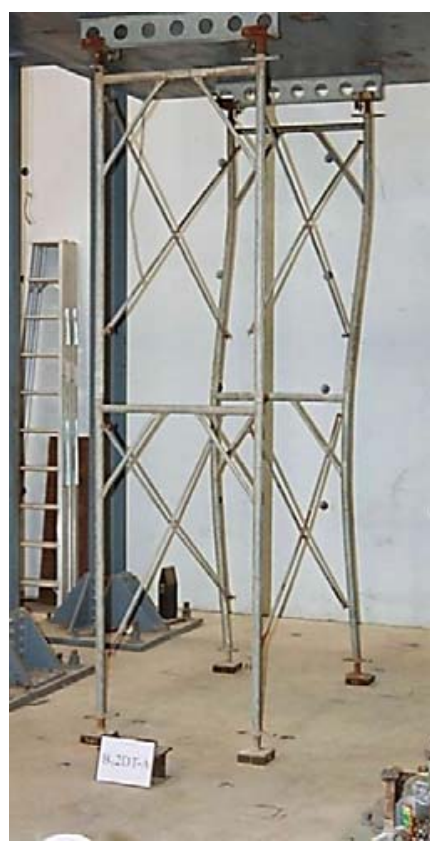

(A) $2 \mathrm{D}$

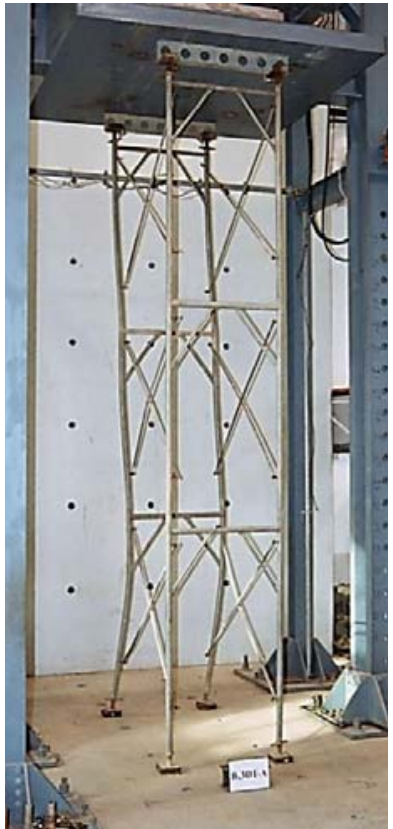

(B) $3 \mathrm{D}$

Figure 13. Failure Modes of One-bay, Two-story (2D) and Three-story (3D) Door-type Steel Scaffolds 


\subsubsection{Combined setup of one-door, one-square, one-rectangle (DSR)}

Average maximum load of the first loadings is $284.28 \mathrm{kN}$, and that of the second loadings is 150.10 $\mathrm{kN}$, which is $53 \%(=150.10 / 284.28)$ of that of the first loadings. Figure 14(A) shows the failure modes of the DSR setup. According to this figure, the deformation occurs mainly on the in-plane of the back row door-type and square-type scaffolds at failure.

\subsubsection{Combined setup of one-door, one-square, two-rectangle (DS2R)}

Average maximum load of the first loadings is $285.08 \mathrm{kN}$, and that of the second loadings is 134.82 $\mathrm{kN}$, which is $47 \%(=134.82 / 285.08)$ of that of the first loadings. Figure 14(B) shows the failure modes of the DS2R setup. According to this figure, the deformation occurs mainly on the in-plane of the back row door-type and square-type scaffolds at failure.

Experimental results demonstrate that the load-carrying capacity of the DS2R setup is close to that of the DSR setup, indicating that the effect of adding one more rectangle steel scaffold on the top of the structure (DSR) on the load-carrying capacity is unapparent.

\subsubsection{Combined setup of two-door, one-square, one-rectangle (2DSR)}

Average maximum load of the first loadings is $239.42 \mathrm{kN}$, and that of the second loadings is 102.97 $\mathrm{kN}$, which is $43 \%(=102.97 / 239.42)$ of that of the first loadings. Figure $14(\mathrm{C})$ shows the failure modes of the 2DSR setup. According to this figure, deformation occurs mainly on the in-plane of the back row between the first and second door-type scaffolds at failure. This finding suggests that the structural stiffness of the door-type steel scaffold is smaller than that of the square-type and rectangle-type steel scaffolds.

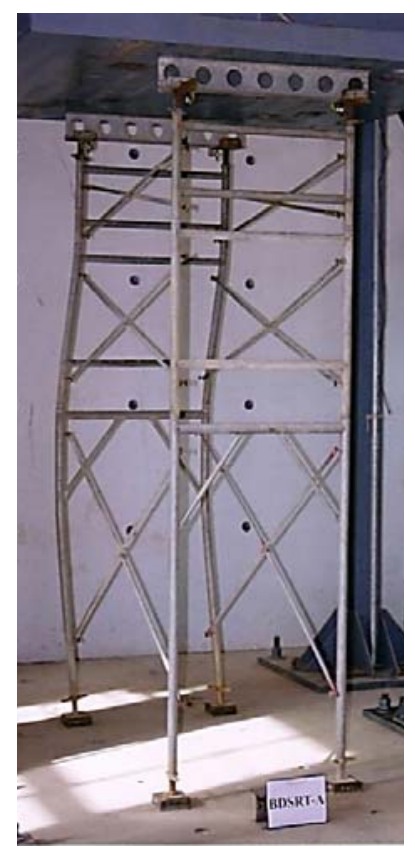

(A) DSR

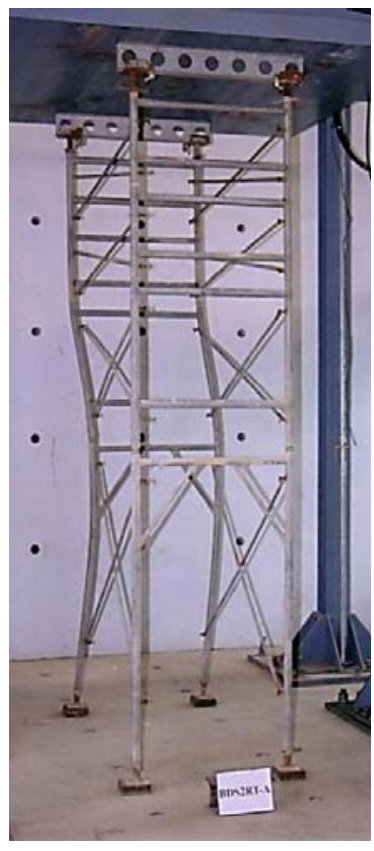

(B) DS2R

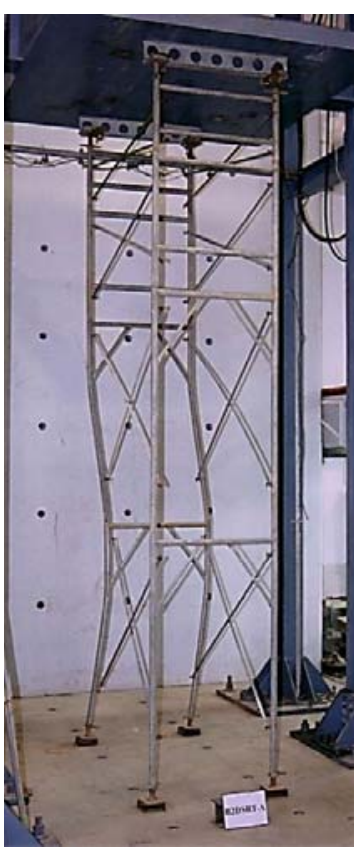

(C) 2DSR

Figure 14. Failure Modes of One-bay DSR, DS2R and 2DSR Setups

According to the test results of one-bay steel scaffolds with different setups, the DS2R setup has the highest load-carrying capacity $(285.08 \mathrm{kN})$, which is $1.42(=285.08 / 200.35)$ times higher than that of the $2 \mathrm{D}$ setup. 


\subsection{Multi-bay Steel Scaffolds}

Based on the lowest and the highest load-carrying capacities and similar heights of the above tests of one-bay steel scaffolds, tests in this section are conducted on two steel scaffolding structures: two-story door-type steel scaffolds (2D) and a combined setup of one-door, one-square, two-rectangle steel scaffolds (DS2R). Each steel scaffolding structure is tested on three multi-bay setups: the two-bay setup, the interlaced three-bay setup, and the interlaced four-bay setup. The two-bay setup is appropriate for smaller and lighter isolated beams, while the interlaced setups are feasible for larger and heavier isolated beams.

Based on the above two steel scaffolding structures, all tests are conducted on six setups of multi-bay steel scaffolds: the two-story door-type, two-bay setup (2D-2B), the interlaced setup of two-story door-type, three-bay (2D-3B), the interlaced setup of two-story door-type, four-bay (2D-4B), the one-door, one-square, two-rectangle, two-bay setup (DS2R-2B), the interlaced setup of one-door, one-square, two-rectangle, three-bay (DS2R-3B), and the interlaced setup of one-door, one-square, two-rectangle, four-bay (DS2R-4B).

Two tests (A and B) are performed for each setup of multi-bay steel scaffold applied by two loadings. Test results of multi-bay steel scaffolds indicate that the failure modes of the six setups of steel scaffolds under both loadings closely resemble each other. The vertical displacements of all the six setups of steel scaffolds under maximum load are less than $20.35 \mathrm{~mm}$. Table 2 summarizes all of the test results.

Table 2. Test Results of Multi-bay Steel Scaffolds

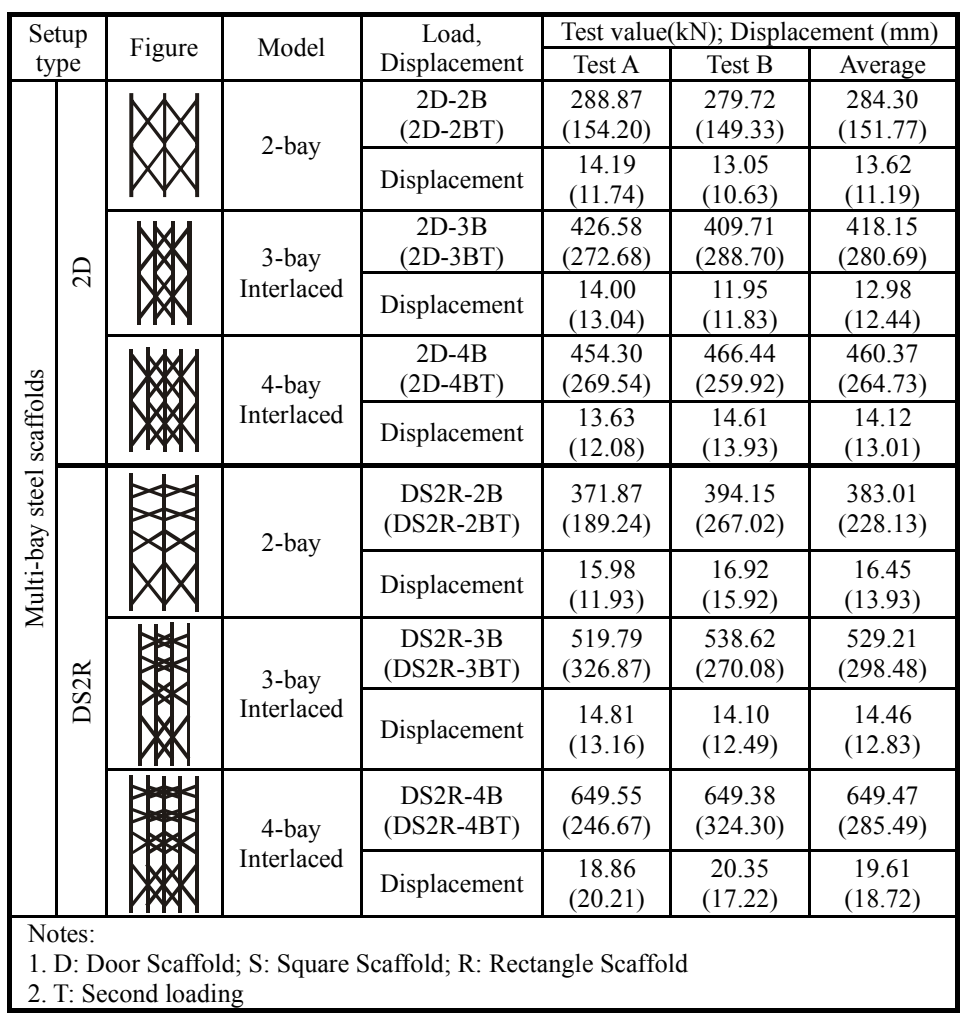




\subsubsection{Two-bay, two-story door-type setup (2D-2B)}

Average maximum load of the first loadings is $284.30 \mathrm{kN}$, and that of the second loadings is 151.77 $\mathrm{kN}$, which is $53 \%(=151.77 / 284.30)$ of that of the first loadings. Figure 15 shows the loads and the vertical displacements of test B of the 2D-2B setup under first and second loadings, respectively. According to Figure 16(A), deformation occurs mainly on the in-plane of the front set and middle set between the first story and the second story of steel scaffolds at failure.

Load-carrying capacity of the two-bay, two-story door-type steel scaffolds (2D-2B) is 1.42 $(=284.30 / 200.35)$ times of that of the one bay, two-story door-type steel scaffolds (2D). This finding suggests that the multi-bay setup can increase the load-carrying capacity.

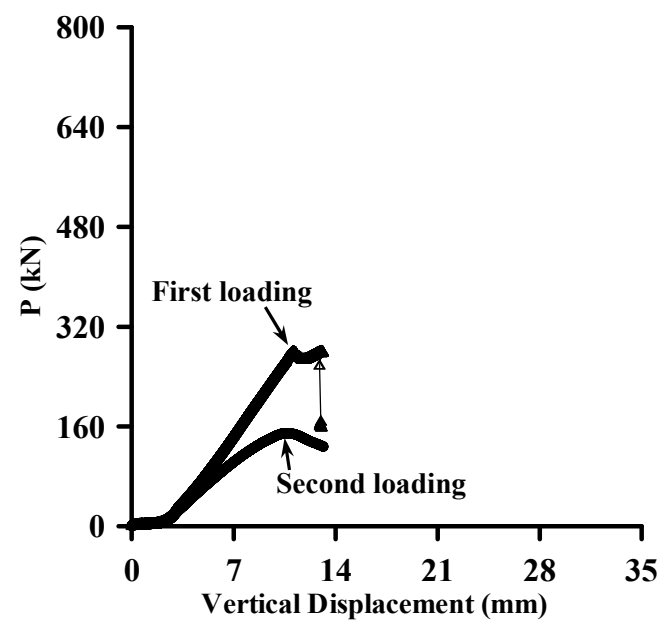

Figure 15. Loads and Vertical Displacements of Two-bay, Two-story Door-type Steel Scaffolds (2D-2B) in Test B

\subsubsection{Interlaced setup of three-bay, two-story door-type (2D-3B)}

Average maximum load of the first loadings is $418.15 \mathrm{kN}$, and that of the second loadings is 280.69 $\mathrm{kN}$, which is $67 \%(=280.69 / 418.15)$ of that of the first loadings. According to Figure 16(B), deformation occurs mainly on the in-plane of the last set between the first story and the second story of steel scaffolds at failure.

Load-carrying capacity of the three-bay, two-story door-type steel scaffolds (2D-3B) is 2.09 $(=418.15 / 200.35)$ times of that of the one bay, two-story door-type steel scaffolds (2D). This finding reveals that the interlaced multi-bay setup can increase the load-carrying capacity.

\subsubsection{Interlaced setup of four-bay, two-story door-type (2D-4B)}

Average maximum load of the first loadings is $460.37 \mathrm{kN}$ and that of the second loadings is 264.73 $\mathrm{kN}$, which is $58 \%(=264.73 / 460.37)$ of that of the first loadings. According to Figure 16(C), deformation occurs mainly on the in-plane of the first and the third sets between the first story and the second story of steel scaffolds at failure.

Load-carrying capacity of the four-bay, two-story door-type steel scaffolds (2D-4B) is 2.30 $(=460.37 / 200.35)$ times of that of the one bay, two-story door-type steel scaffolds (2D). This finding suggests that the load-carrying capacity increases with the number of bays in interlaced setups. 


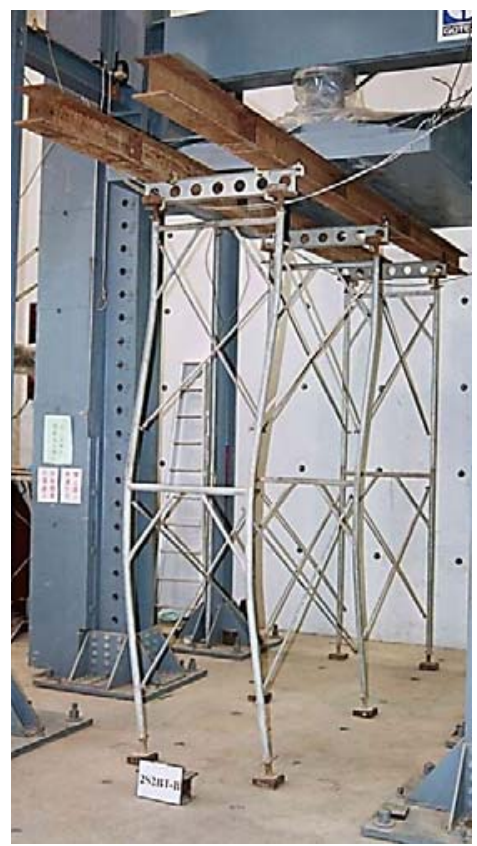

(A) 2D-2B

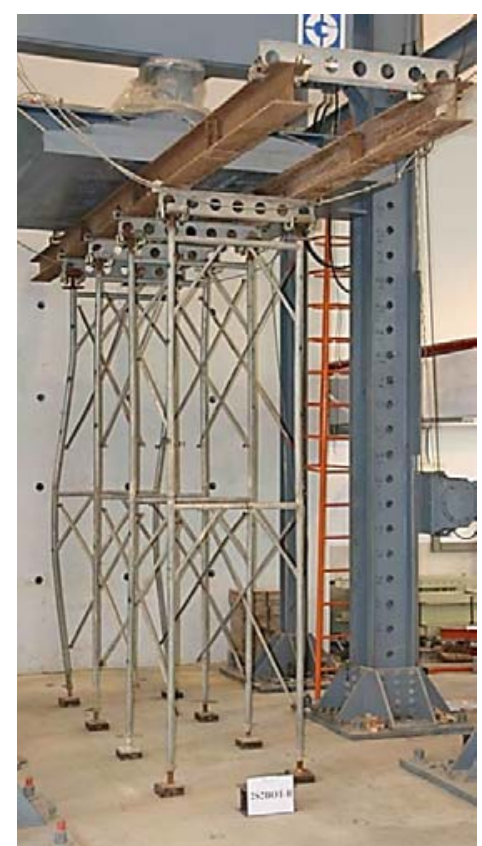

(B) 2D-3B

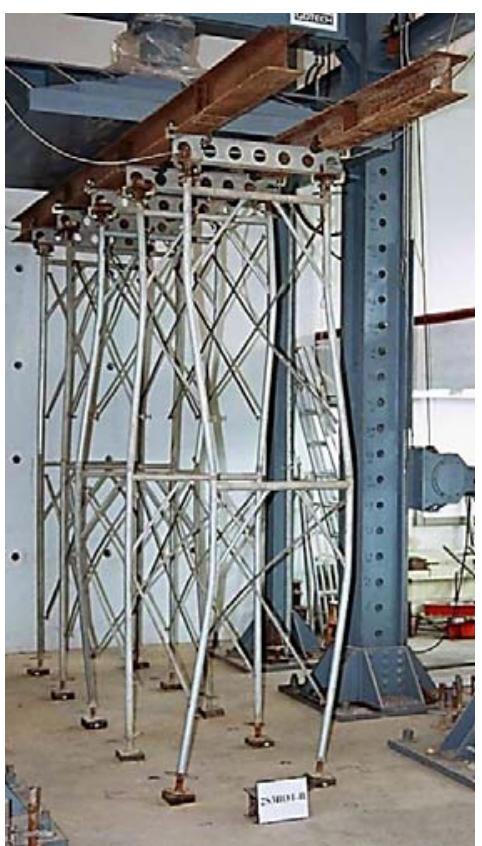

(C) 2D-4B

Figure 16. Failure Modes of 2D-2B, 2D-3B and 2D-4B Setups

\subsubsection{Two-bay, one-door, one-square, two-rectangle setup (DS2R-2B)}

Average maximum load of the first loadings is $383.01 \mathrm{kN}$, and that of the second loadings is 228.13 $\mathrm{kN}$, which is $60 \%(=228.13 / 383.01)$ of that of the first loadings. According to Figure 17(A), deformation occurs mainly on the in-plane of the last and the middle sets between the first story and the second story of steel scaffolds at failure.

Load-carrying capacity of the DS2R-2B setup is $1.34(=383.01 / 285.08)$ times of that of the DS2R setup. This finding demonstrates that under the circumstances of the DS2R setup, the multi-bay setup can increase the load-carrying capacity.

\subsubsection{Interlaced setup of three-bay, one-door, one-square, two-rectangle (DS2R-3B)}

Average maximum load of the first loadings is $529.21 \mathrm{kN}$ and that of the second loadings is 298.48 $\mathrm{kN}$, which is $56 \%(=298.48 / 529.21)$ of that of the first loadings. According to Figure 17(B), deformation occurs mainly on the in-plane of the last two sets between the first story and the second story of steel scaffolds at failure.

Load-carrying capacity of the interlaced setup of DS2R-3B is $1.86(=529.21 / 285.08)$ times of that of the DS2R setup. This finding demonstrates that the interlaced multi-bay setup can increase the load-carrying capacity.

\subsubsection{Interlaced setup of four-bay, one-door, one-square, two-rectangle (DS2R-4B)}

Average maximum load of the first loadings is $649.47 \mathrm{kN}$, and that of the second loadings is 285.49 $\mathrm{kN}$, which is $44 \%(=285.49 / 649.47)$ of that of the first loadings. According to Figure 17(C), deformation occurs mainly on the in-plane of the third, the fourth and the last sets between the first story and the second story of steel scaffolds at failure. 
Load-carrying capacity of the interlaced setup of DS2R-4B is $2.28(=649.47 / 285.08)$ times of that of the DS2R setup. This finding suggests that the interlaced multi-bay setup can increase the load-carrying capacity. Moreover, a higher number of bays implies a higher load-carrying capacity.

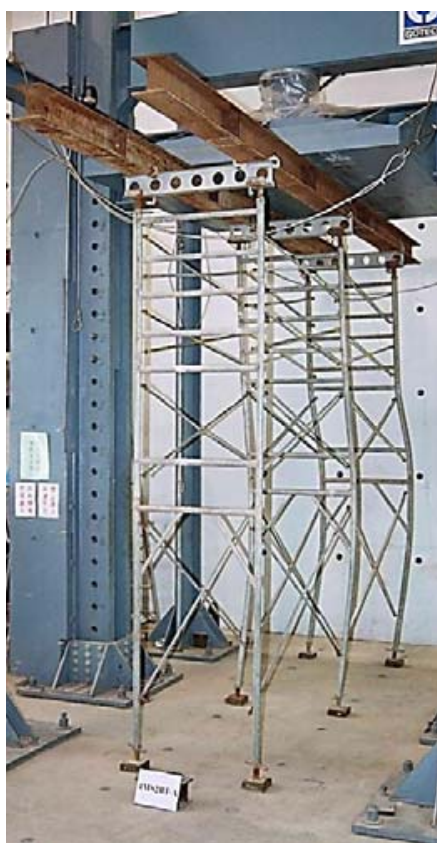

(A) DS2R-2B

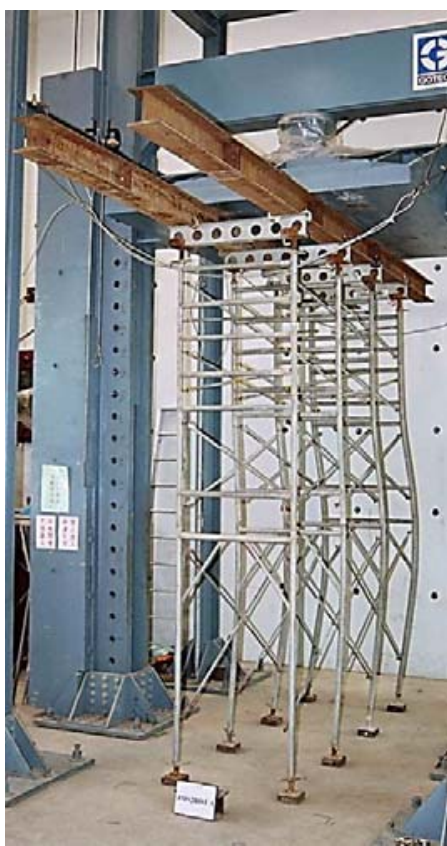

(B) DS2R-3B

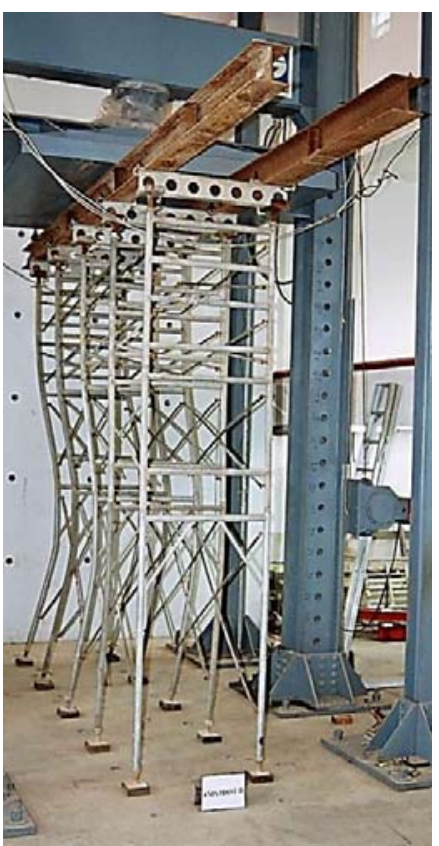

(C) DS2R-4B

Figure 17. Failure Modes of DS2R-2B, DS2R-3B and DS2R-4B Setups

\subsection{One-bay Steel Scaffolds with Defects}

Tests are performed on four types of one-bay steel scaffolds with defects. Arrangements of these scaffolding structures are the same as those of one-bay steel scaffolds. The four types of tests are defined as two-story door-type scaffolds with defects (Df-2D), three-story door-type scaffolds with defects (Df-3D), combined setup of one-door, one-square, one-rectangle scaffolds with defects (Df-DSR), and combined setup of two-door, one-square, one-rectangle scaffolds with defects (Df-2DSR).

Since the test results on steel scaffolds with defects have larger errors than that of steel scaffolds without defects, the four tests (A, B, C and D) are generally performed by the one-bay steel scaffold with defects applied by two loadings. Test results of one-bay steel scaffolds with defects indicate that the failure modes of these four setups of steel scaffolds under both loadings closely resemble each other. Vertical displacements of all four types of steel scaffolds under maximum load are less than $11.02 \mathrm{~mm}$. Table 3 summarizes all of the tests results. 
Table 3. Test Results of One-bay Steel Scaffolds with Defects

\begin{tabular}{|c|c|c|c|c|c|c|c|c|c|}
\hline \multirow{2}{*}{\multicolumn{2}{|c|}{$\begin{array}{l}\text { Setup } \\
\text { type }\end{array}$}} & \multirow{2}{*}{ Figure } & \multirow{2}{*}{$\begin{array}{l}\text { Height } \\
(\mathrm{cm})\end{array}$} & \multirow{2}{*}{$\begin{array}{c}\text { Load, } \\
\text { Displacement }\end{array}$} & \multicolumn{5}{|c|}{ Test value (kN); Displacement (mm) } \\
\hline & & & & & Test A & Test B & Test C & Test D & Average \\
\hline \multirow{2}{*}{\multicolumn{2}{|c|}{ 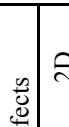 }} & & \multirow{2}{*}{375.00} & $\begin{array}{c}\text { Df-2D } \\
\text { (Df-2DT) }\end{array}$ & $\begin{array}{c}142.81 \\
(117.55)\end{array}$ & $\begin{array}{l}100.08 \\
(81.76)\end{array}$ & $\begin{array}{c}174.65 \\
(135.64)\end{array}$ & $\begin{array}{c}142.53 \\
(118.99)\end{array}$ & $\begin{array}{c}140.02 \\
(113.49)\end{array}$ \\
\hline & & & & Displacement & $\begin{array}{c}7.97 \\
(7.20)\end{array}$ & $\begin{array}{c}9.93 \\
(12.55)\end{array}$ & $\begin{array}{c}7.01 \\
(6.71)\end{array}$ & $\begin{array}{c}5.85 \\
(6.13)\end{array}$ & $\begin{array}{c}7.69 \\
(8.15)\end{array}$ \\
\hline $\begin{array}{l}\frac{0}{0} \\
\frac{7}{7} \\
\frac{5}{3}\end{array}$ & \multirow{2}{*}{ ले } & & \multirow{2}{*}{545.00} & $\begin{array}{c}\text { Df-3D } \\
\text { (Df-3DT) }\end{array}$ & $\begin{array}{l}116.22 \\
(89.97)\end{array}$ & $\begin{array}{c}170.72 \\
(128.58)\end{array}$ & $\begin{array}{c}184.95 \\
(142.87)\end{array}$ & $\begin{array}{l}129.53 \\
(98.33)\end{array}$ & $\begin{array}{c}150.36 \\
(114.94)\end{array}$ \\
\hline$\frac{0}{0}$ & & & & Displacement & $\begin{array}{c}9.96 \\
(15.79)\end{array}$ & $\begin{array}{c}9.80 \\
(8.69)\end{array}$ & $\begin{array}{l}10.09 \\
(8.90)\end{array}$ & $\begin{array}{c}9.92 \\
(11.24)\end{array}$ & $\begin{array}{c}9.94 \\
(11.16)\end{array}$ \\
\hline $\begin{array}{l}\tilde{J} \\
\text { D } \\
\end{array}$ & \multirow{4}{*}{ 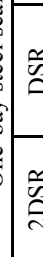 } & \multirow[t]{2}{*}{ 目 } & \multirow{2}{*}{345.30} & $\begin{array}{c}\text { Df-DSR } \\
\text { (Df-DSRT) }\end{array}$ & $\begin{array}{c}280.36 \\
(166.64)\end{array}$ & $\begin{array}{c}271.33 \\
(118.11)\end{array}$ & $\begin{array}{c}249.61 \\
(182.10)\end{array}$ & $\begin{array}{c}214.13 \\
(164.57)\end{array}$ & $\begin{array}{c}253.86 \\
(157.86)\end{array}$ \\
\hline 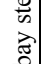 & & & & Displacement & $\begin{array}{l}10.76 \\
(7.19)\end{array}$ & $\begin{array}{l}11.02 \\
(9.50)\end{array}$ & $\begin{array}{l}10.40 \\
(8.85)\end{array}$ & $\begin{array}{l}10.65 \\
(7.59)\end{array}$ & $\begin{array}{l}10.71 \\
(8.28)\end{array}$ \\
\hline Ő & & \multirow{2}{*}{ 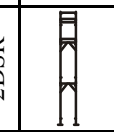 } & \multirow{2}{*}{515.30} & $\begin{array}{c}\text { Df-2DSR } \\
\text { (Df-2DSRT) }\end{array}$ & $\begin{array}{c}179.86 \\
(131.64)\end{array}$ & $\begin{array}{c}205.98 \\
(151.23)\end{array}$ & $\begin{array}{c}206.93 \\
(118.16)\end{array}$ & --- & $\begin{array}{c}197.59 \\
(133.68)\end{array}$ \\
\hline & & & & Displacement & $\begin{array}{c}9.64 \\
(8.48)\end{array}$ & $\begin{array}{c}9.90 \\
(9.17)\end{array}$ & $\begin{array}{l}10.30 \\
(9.75)\end{array}$ & --- & $\begin{array}{c}9.95 \\
(9.13)\end{array}$ \\
\hline \multicolumn{10}{|c|}{$\begin{array}{l}\text { Notes: } \\
\text { 1. D: Door Scaffold; S: Square Scaffold; R: Rectangle Scaffold } \\
\text { 2. Df: Defective; T: Second loading; } \\
\text { 3. ---: Not available }\end{array}$} \\
\hline
\end{tabular}

\subsubsection{Two-story door-type setup with defects (Df-2D)}

Average maximum load of the first loadings is $140.02 \mathrm{kN}$, and that of the second loadings is 113.49 $\mathrm{kN}$, which is $81 \%(=113.49 / 140.02)$ of that of the first loadings. Figure 18 shows the loads and the vertical displacements of test A of the Df-2D setup under first and second loadings, respectively. According to Figure 19(A), deformation occurs mainly on the in-plane of the front set between the first story and the second story of steel scaffolds at failure. Load-carrying capacity of the Df-2D setup is $70 \%(=140.02 / 200.35)$ of that of the $2 \mathrm{D}$ setup.

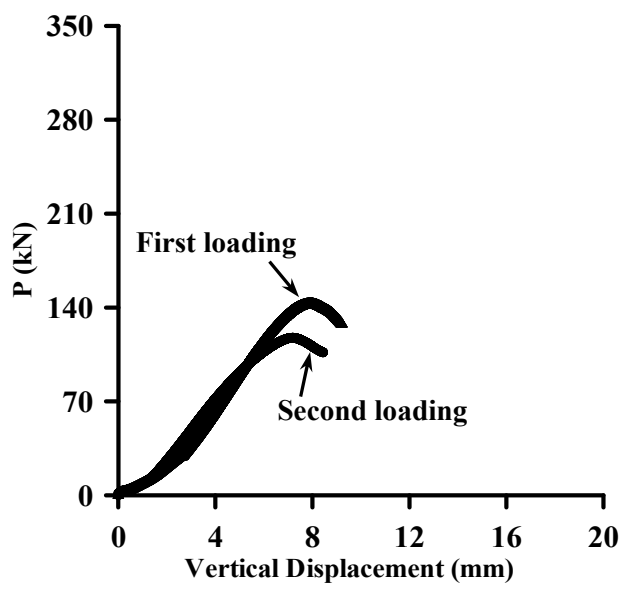

Figure 18. Loads and Vertical Displacements of One-bay, Two-story Door-type Steel Scaffolds with Defects (Df-2D) in Test A

\subsubsection{Three-story door-type setup with defects (Df-3D)}

Average maximum load of the first loadings is $150.36 \mathrm{kN}$, and that of the second loadings is 114.94 $\mathrm{kN}$, which is $76 \%(=114.94 / 150.36)$ of that of the first loadings. According to Figure 19(B), deformation occurs mainly on the in-plane of the back set of the first, the second and the third stories of steel scaffolds at failure. Load-carrying capacity of the Df-3D setup is $75 \%$ $(=150.36 / 199.59)$ of that of the 3D setup. 


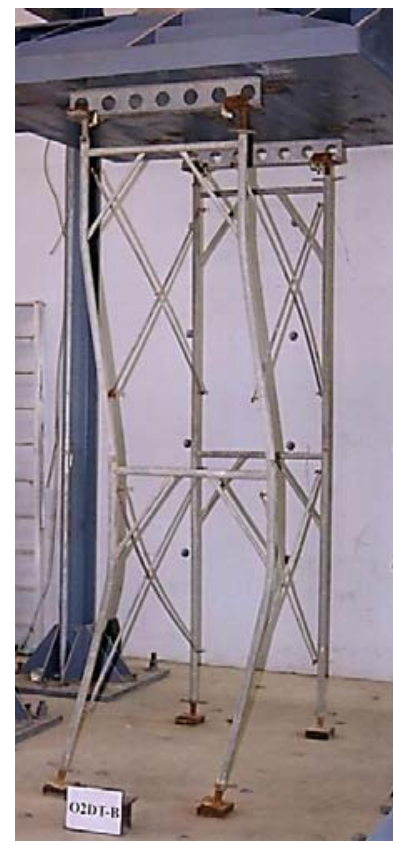

(A) Df-2D

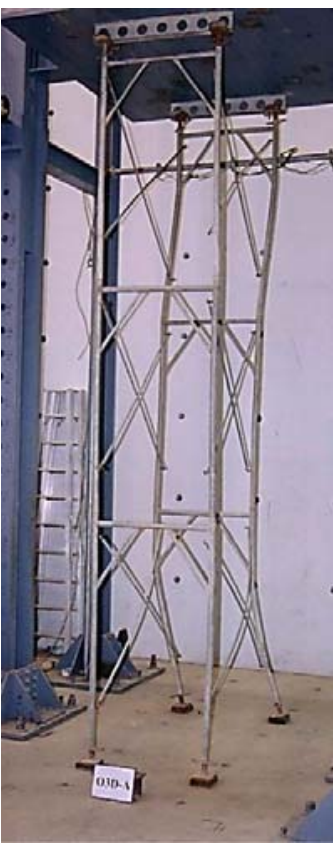

(B) Df-3D

Figure 19. Failure Modes of One-bay Df-2D and Df-3D Setups with Defects

\subsubsection{Combined setup of one-door, one-square, one-rectangle with defects (Df-DSR)}

Average maximum load of the first loadings is $253.86 \mathrm{kN}$, and that of the second loadings is 157.86 $\mathrm{kN}$, which is $62 \%(=157.86 / 253.86)$ of that of the first loadings. According to Figure 20(A), deformation occurs mainly on the in-plane of the back set between the first story and the second story of steel scaffolds at failure. Load-carrying capacity of the Df-DSR setup is $89 \%$ $(=253.86 / 284.28)$ of that of the DSR setup.

\subsubsection{Combined setup of two-door, one-square, one-rectangle with defects (Df-2DSR)}

Three tests (A, B and C) are performed for this setup. Average maximum load of the first loadings is $197.59 \mathrm{kN}$, and that of the second loadings is $133.68 \mathrm{kN}$, which is $68 \%(=133.68 / 197.59)$ of that of the first loadings. According to Figure 20(B), deformation occurs mainly on the in-plane of the back set between the first story and the second story of steel scaffolds at failure. Load-carrying capacity of the Df-2DSR setup is $83 \%(=197.59 / 239.42)$ of that of the 2DSR setup.

\section{COMPARISON OF LOAD-CARRYING CAPACITIES OF STEEL SCAFFOLDS}

\subsection{Comparison of Load-carrying Capacities between Steel Scaffolds with and without Defects}

Figure 21 compares the test results of one-bay steel scaffolds with and without defects. According to Figure 21, the load-carrying capacities of steel scaffolds with defects reduce to 70 89\% of those of the steel scaffolds without defects. Basically, we recommend avoiding the use of defective materials to set up steel scaffolds on a construction site. However, if the steel scaffolds with defects are used on the construction site, the reduction of load-carrying capacity of the defective steel scaffolds should be considered when engineers design the scaffolding structure. 


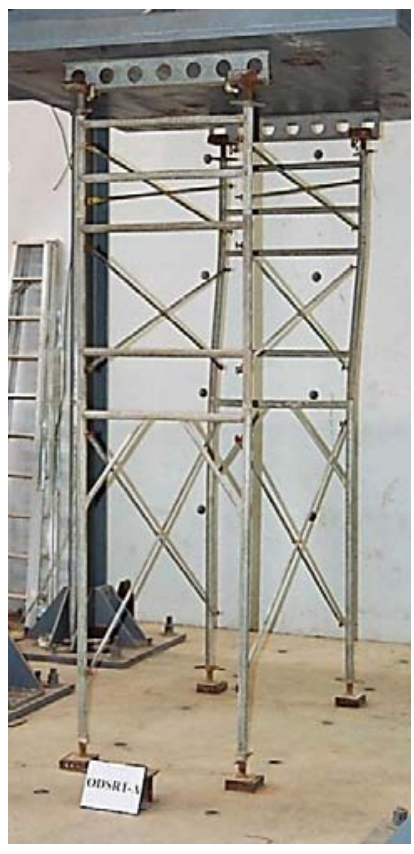

(A) Df-DSR

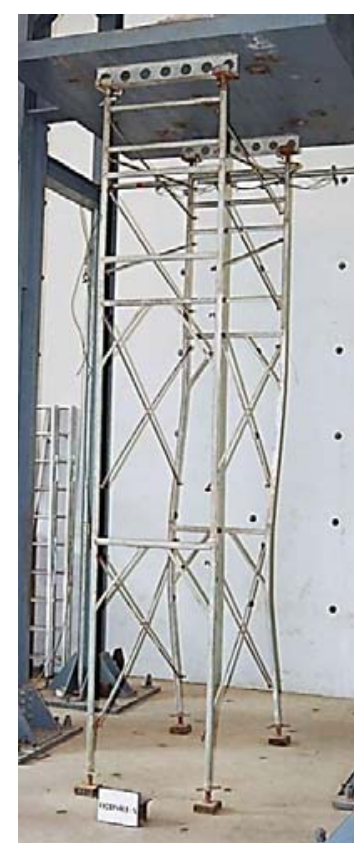

(B) Df-2DSR

Figure 20. Failure Modes of One-bay Df-DSR and Df-2DSR Setups with Defects

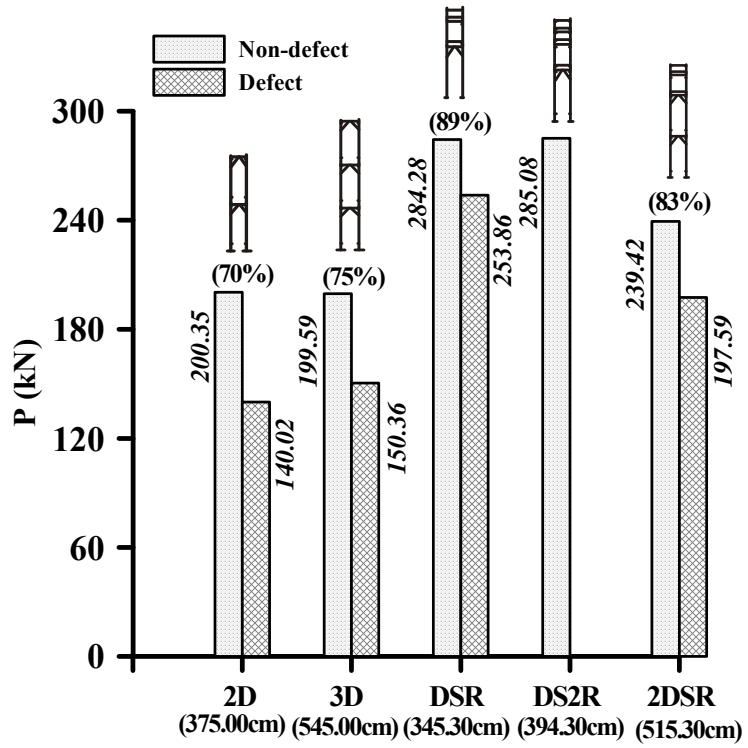

Figure 21. Comparison of Load-carrying Capacities of One-bay Steel Scaffolds with and without Defects in Different Setups

\subsection{Multi-bay 2D Setup}

Figure 22 compares the test results of two-story door-type steel scaffolds with one-bay and multi-bay setups at a height of $375.00 \mathrm{~cm}$. According to this figure, load-carrying capacities of the multi-bay steel scaffolds increase with the number of bays. Additionally, the load-carrying capacity of the 2D-2B setup is $1.42(=284.30 / 200.35)$ times of that of the $2 \mathrm{D}$ setup, the $2 \mathrm{D}-3 \mathrm{~B}$ setup is $2.09(=418.15 / 200.35)$ times of that of the $2 \mathrm{D}$ setup, and the $2 \mathrm{D}-4 \mathrm{~B}$ setup is 2.30 $(=460.37 / 200.35)$ times of that of the 2D setup. 


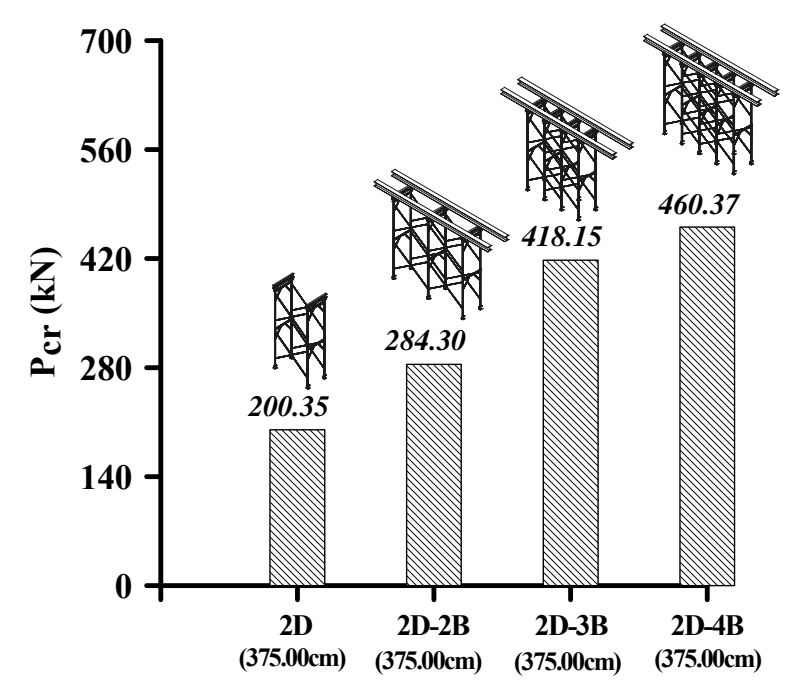

Figure 22. Comparison of Load-carrying Capacities of One-bay and Multi-bay Two-story Door-type Steel Scaffolds (2D)

Comparing the 2D-2B setup and the 2D-4B setup, which have the same overall length $(366.00 \mathrm{~cm})$ and width $(91.50 \mathrm{~cm})$, reveals that the load-carrying capacity of the 2D-4B setup is 1.62 $(=460.37 / 284.30)$ times of that of the 2D-2B setup. This is owing to that the 2D-4B setup has two more sets of steel scaffolds than those of the 2D-2B setup within the same length.

When the test results are divided by the number of sets, the load-carrying capacities of the set of the single-row steel scaffolds in 2D, 2D-2B, 2D-3B, and 2D-4B setups are $100.18 \mathrm{kN}(=200.35 / 2)$, $94.77 \mathrm{kN}(=284.30 / 3), 104.54 \mathrm{kN}(=418.15 / 4)$, and $92.07 \mathrm{kN}(=460.37 / 5)$, respectively. The average load-carrying capacity of a set of the four setups of single-row steel scaffolds is $97.89 \mathrm{kN}$ $(=(100.18+94.77+104.54+92.07) / 4)$. The data multiplied by the number of sets can provide a valuable reference for quickly estimating the load-carrying capacity of single-row, multi-bay, two-story door-type steel scaffolds.

\subsection{Multi-bay DS2R Setup}

Figure 23 compares the test results of one-door, one-square, two-rectangle steel scaffolds (DS2R) with one-bay and multi-bay setups at a height of $394.30 \mathrm{~cm}$. According to Figure 23, load-carrying capacities of the multi-bay DS2R steel scaffolds increase with the number of bays. Additionally, the load-carrying capacity of the two-bay DS2R setup (DS2R-2B) is 1.34 $(=383.01 / 285.08)$ times of that of the one-bay DS2R setup, the three-bay DS2R setup (DS2R-3B) is $1.86(=529.21 / 285.08)$ times of that of the one-bay DS2R setup, and the four-bay DS2R setup (DS2R-4B) is $2.28(=649.47 / 285.08)$ times of that of the one-bay DS2R setup.

Comparing the DS2R-2B setup and DS2R-4B setup which have the same overall length $(366.00 \mathrm{~cm})$ and width $(91.50 \mathrm{~cm})$ reveals that the load-carrying capacity of the DS2R-4B setup is 1.70 $(=649.47 / 383.01)$ times of that of the DS2R-2B setup. This is owing to that the DS2R-4B setup has two more sets of steel scaffolds than those of the DS2R-2B setup within the same length.

When the test results are divided by the number of sets, the load-carrying capacities of the set of the single-row steel scaffolds in DS2R, DS2R-2B, DS2R-3B, and DS2R-4B setups are $142.54 \mathrm{kN}$ $(=285.08 / 2), 127.67 \mathrm{kN}(=383.01 / 3), 132.30 \mathrm{kN}(=529.21 / 4)$, and $129.89 \mathrm{kN}(=649.47 / 5)$, respectively. The average load-carrying capacity of a set of the four setups of single-row steel 
scaffolds is $133.10 \mathrm{kN}(=(142.54+127.67+132.30+129.89) / 4)$. This load-carrying capacity multiplied by the number of sets provides a valuable reference for efforts to fast estimate the load-carrying capacity of single-row, multi-bay, one-door, one-square, two-rectangle steel scaffolds.

Although the height $(394.30 \mathrm{~cm})$ of the DS2R setup described in this section is higher than that $(375.00 \mathrm{~cm})$ of the $2 \mathrm{D}$ setup described in the previous one, the average load-carrying capacity of a set of the DS2R setup $(133.10 \mathrm{kN})$ is higher than that of a set of the $2 \mathrm{D}$ setup $(97.89 \mathrm{kN})$. This finding demonstrates that the load-carrying capacity of the combined setup of steel scaffolds is higher than that of two-story door-type steel scaffolds. Moreover, the rectangle and the square steel scaffolds can increase the load-carrying capacity of the steel scaffolds.

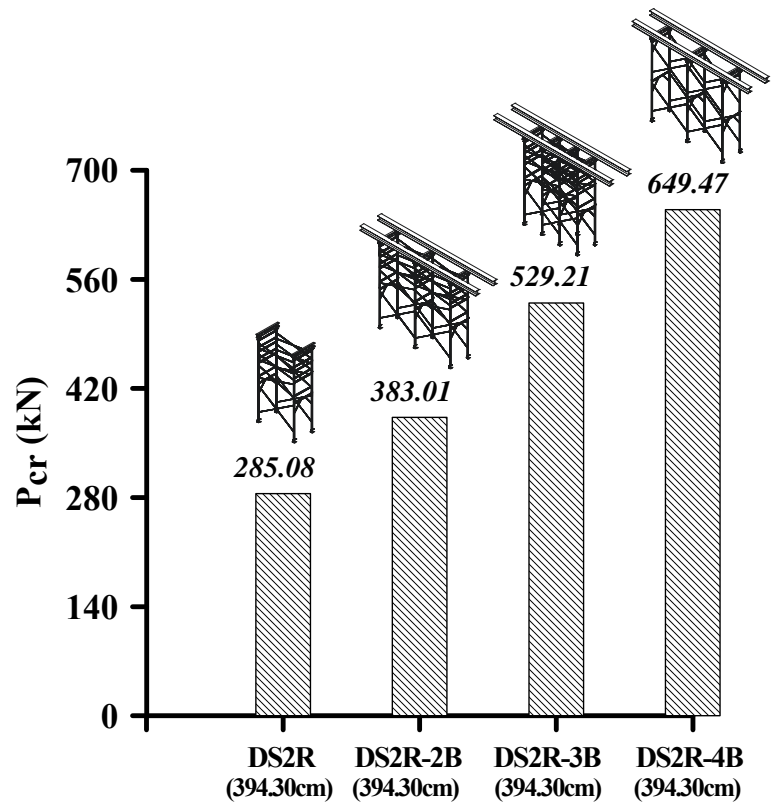

Figure 23. Comparison of Load-carrying Capacities of One-bay and Multi-bay DS2R Setups

\subsection{Estimate Load-carrying Capacities of Single-row, Multi-set Scaffolds based on those of Single-row, One-set Scaffolds}

For convenience, when designing the strength of steel scaffolds, the designer can estimate the load-carrying capacities of single-row, multi-set steel scaffolds based on those of single-row, one-set steel scaffolds. Notably, the load-carrying capacities of one-set steel scaffolds for these two setups (2D and DS2R) can be obtained when the load-carrying capacities of the single-row, one-bay 2D setup $(200.35 \mathrm{kN})$ and DS2R setup $(285.08 \mathrm{kN})$ are divided by 2, respectively. Therefore, multiplying the load-carrying capacity of one-set steel scaffolds by the number of sets obtains the estimated load-carrying capacities of multi-set steel scaffolds for these two setups (Table 4).

Table 4 lists the estimated and real values of the load-carrying capacities of single-row, multi-set steel scaffolds in two setups (2D and DS2R). The average estimating factor of the $2 \mathrm{D}$ setup is 0.97 , explaining why average load-carrying capacity of the 2D setup increases $97.17 \mathrm{kN}$ $(=100.18 \times 0.97)$ for each additional set. Additionally, average estimating factor of the DS2R setup is 0.91 , explaining why average load-carrying capacity of the DS2R setup increases $129.71 \mathrm{kN}$ $(=142.54 \times 0.91)$ for each additional set. 
Table 4. Estimated Value and Real Value of the Load-carrying Capacities of Single-row, Multi-set Steel Scaffolds

\begin{tabular}{|c|c|c|c|c|c|c|c|c|c|}
\hline \multirow{2}{*}{$\begin{array}{l}\text { Setup } \\
\text { type }\end{array}$} & \multirow[b]{2}{*}{ Figure } & \multirow[b]{2}{*}{ Comparison } & \multicolumn{7}{|c|}{ Load-carrying capacity $(\mathrm{kN})$} \\
\hline & & & $\begin{array}{c}\text { Single-row, } \\
\text { one-bay }\end{array}$ & 1 set & 2 sets & 3 sets & 4 sets & 5 sets & Average \\
\hline \multirow{3}{*}{ ลิ } & \multirow{3}{*}{4} & $\begin{array}{l}\text { Estimated } \\
\text { value } \\
\text { (A) }\end{array}$ & --- & 100.18 & 200.35 & 300.53 & 400.70 & 500.88 & \\
\hline & & $\begin{array}{l}\text { Real value } \\
\text { (B) }\end{array}$ & 200.35 & --- & 200.35 & 284.30 & 418.15 & 460.37 & \\
\hline & & $\begin{array}{l}\text { Estimating } \\
\text { factor } \\
\text { (B)/(A) }\end{array}$ & --- & --- & --- & 0.95 & 1.04 & 0.92 & 0.97 \\
\hline \multirow{3}{*}{$\begin{array}{l}\widetilde{\approx} \\
\tilde{n} \\
\tilde{n}\end{array}$} & \multirow{3}{*}{ 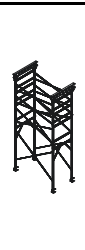 } & $\begin{array}{l}\text { Estimated } \\
\text { value } \\
\text { (C) }\end{array}$ & --- & 142.54 & 285.08 & 427.62 & 570.16 & 712.70 & \\
\hline & & $\begin{array}{l}\text { Real value } \\
\text { (D) }\end{array}$ & 285.08 & --- & 285.08 & 383.01 & 529.21 & 649.47 & \\
\hline & & $\begin{array}{l}\text { Estimating } \\
\text { factor } \\
\text { (D)/(C) }\end{array}$ & --- & --- & --- & 0.90 & 0.93 & 0.91 & 0.91 \\
\hline \multicolumn{10}{|c|}{$\begin{array}{l}\text { Notes: } \\
\text { 1. D: Door Scaffold, S: Square Scaffold, R: Rectangle Scaffold } \\
\text { 2. --: Not available }\end{array}$} \\
\hline
\end{tabular}

On a construction site, the designer can quickly estimate the load-carrying capacities of single-row, multi-set (or multi-bay) steel scaffolds for various setups. Additionally, load-carrying capacities of steel scaffolds with different stories can be calculated by determining the analytical parameters of the steel scaffolds used in this study through numerical analyses in future research. However, the estimating factors must be verified with a large number of tests. This study only provides preliminary findings as a reference for designers to quickly estimate the load-carrying capacities of single-row, multi-set steel scaffolds.

\section{LOWER BOUND OF LOAD-CARRYING CAPACITY OF REUSABLE SCAFFOLDS}

This study also investigates the load-carrying capacity reduction of the reusable steel scaffolds in the worst condition on the construction site. After the first loading, the steel scaffolds are reset and a second loading is applied. Test results of the second loading can be regarded as the worst condition of the reusable steel scaffolds on the construction site, which can be compared with those of the first loading. Moreover, the load-carrying capacities of the reusable steel scaffolds in the worst condition can also be compared with those of the steel scaffolds with defects.

Figure 24 compares the load-carrying capacities of the reusable steel scaffolds subtracting one to three-fold standard deviations. According to this figure, the average ratio of dividing the load-carrying capacities of the second loading by those of the first loading is $\mu=0.63$, with a standard deviation of $\sigma=0.13$. Additionally, according to Figure 21, the ratio of load-carrying capacity of the steel scaffolds with defects to those without defects is $70 \sim 89 \%$, which is higher than that of the reusable steel scaffolds in the worst condition $(63 \%)$. This finding demonstrates that the strength of the steel scaffolds with defects is still reusable.

Figure 24 also shows various situations with different standard deviations. Subtracting one-fold standard deviation from the average ratio of the reusable steel scaffolds $(\mu-\sigma)$ yields 0.50 . Moreover, subtracting two-fold standard deviations $(\mu-2 \sigma)$ yields 0.37 . Also, subtracting three-fold standard deviations $(\mu-3 \sigma)$ yields 0.24 . Above results can be regarded as the strength reduction factors $(\phi)$ of the reusable steel scaffolds. The designer can select proper strength 
reduction factors $(\phi)$ of reusable scaffolds based on project fund and safety requirements. These factors can provide a valuable reference for determining the strength reduction of the reusable steel scaffolds.

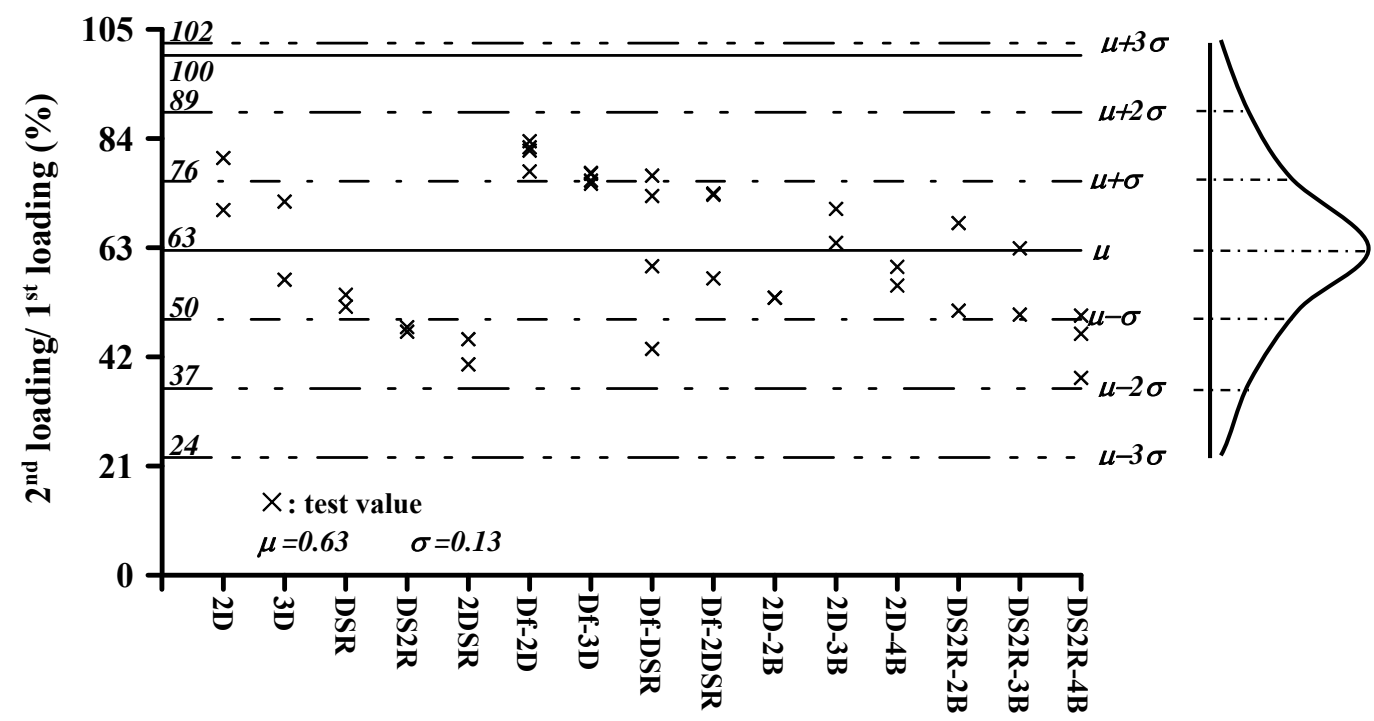

Figure 24. Comparison of Load-carrying Capacities of Reusable Steel Scaffolds Subtracting and Adding One to Three-fold Standard Deviations

\section{VERTICAL DISPLACEMENTS OF STEEL SCAFFOLDS AT FAILURE}

In various tests on the single-row, one-bay steel scaffolds both with and without defects, the vertical displacements of all of the scaffolding structures at maximum load are less than $12.74 \mathrm{~mm}$. In tests on the single-row, multi-bay 2D setup and the multi-bay DS2R setup, the vertical displacements of all of the scaffolding structures at maximum load are less than $20.35 \mathrm{~mm}$. Above test results can serve as a valuable reference for contractors in designing the isolated reinforced concrete beams if the construction accuracy must be considered.

\section{CONCLUSIONS}

This study explored the structural behaviors of single-row steel scaffolds with various setups to determine the load-carrying capacities and failure modes of these scaffolding structures. Experimental results indicate that the load-carrying capacities of one-bay, three-story door-type steel scaffolds (3D) are close to those of two-story door-type steel scaffolds (2D). Additionally, deformation occurs mainly in the in-plane direction of the steel scaffolds at failure. Load-carrying capacity of the 2D-2B setup is 1.42 times of that of the 2D setup. Also, load-carrying capacities of the 2D-3B and 2D-4B setups are 2.09 times and 2.30 times of that of the 2D setup, respectively. Moreover, although with the same overall length, load-carrying capacity of the 2D-4B setup is 1.62 times of that of the $2 \mathrm{D}-2 \mathrm{~B}$ setup. This finding demonstrates that increasing the number of bays can increase the load-carrying capacity of door-type steel scaffolds.

Load-carrying capacity of the two-bay DS2R setup (DS2R-2B) is 1.34 times of that of the one-bay DS2R setup. Also, load-carrying capacities of the three-bay DS2R setup (DS2R-3B) and four-bay DS2R setup (DS2R-4B) are 1.86 times and 2.28 times of that of the one-bay DS2R setup, respectively. This finding demonstrates that increasing the number of bays can increase the 
load-carrying capacity of these steel scaffolds. Additionally, load-carrying capacity of the 2D setup and the DS2R setup increases $97.17 \mathrm{kN}$ and $129.71 \mathrm{kN}$ on average for each additional set, respectively. Designers can quickly estimate the load-carrying capacities of multi-set steel scaffolds by multiplying the load-carrying capacity of one-set steel scaffolds by the number of sets.

In this study, test results of the second loading are regarded as the worst condition of the reusable steel scaffolds on the a construction site. The average ratio of dividing the load-carrying capacities of the second loading by those of the first loading is $\mu=0.63$, with a standard deviation of $\sigma=0.13$. Additionally, subtracting one to three -fold standard deviation from the average ratio of the reusable steel scaffolds [i.e., $(\mu-\sigma),(\mu-2 \sigma),(\mu-3 \sigma)$ ] yields the strength reduction factors () of the reusable steel scaffolds, $0.50,0.37$, and 0.24 , respectively. Designers can select appropriate strength reduction factors of reusable scaffolds, based on the design requirements.

Test results of steel scaffolds with defects indicate that the ratio of load-carrying capacity of the steel scaffolds with defects to those without defects is higher than that of the steel scaffolds using the second loading condition to those using the first loading condition. This finding demonstrates that the steel scaffolds with defects are not yet in the worst quality condition on the construction site. Additionally, when under a maximum load, the vertical displacements of all setups of multi-bay steel scaffolds are less than $20.35 \mathrm{~mm}$. If the construction accuracy of the isolated reinforced concrete beams must be considered, the data can serve as a valuable reference for allowable deformation.

\section{ACKNOWLEDGEMENTS}

The authors would like to thank the National Science Council, Taiwan, for financially supporting this research under Contract No. NSC 102-2221-E-224-044. Pin-Huei Construction \& Engineering Co., Ltd. and Ruentex Engineering \& Construction Co., Ltd. are appreciated for providing the testing materials. Mr. Jhih-Wei Guo is commended for his assistance in conducting the tests.

\section{REFERENCES}

[1] Chan, S.L. and Peng, J.L., "Performance-based Design of Steel Scaffolding Systems by Stability Analysis", Invited Lecture, International Conference on Structural Stability and Dynamics, 7-9 Dec. 2000, Organised by National Taiwan University, proceedings edited by Yang, Y.B., Leu, L.J. and Hsieh, S.H., pp. 205-210.

[2] Chan, S.L., Chu, A.Y.T. and Albermani, F.G., "Stability and Simulation-based Design of Steel Scaffolding without Using the Effective Length Method", Structural Stability and Dynamics, 2003, Vol. 3, No. 4, pp. 443-460.

[3] Huang, Y.L., Kao, Y.G. and Rosowsky, D.V., "Load-carrying Capacities and Failure Modes of Scaffolding Shoring Systems, Part II: Analytical model and its closed-form Solution", Structural Engineering and Mechanics, 2000, Vol. 10, No. 1, pp. 53-66.

[4] Liu, H.B., Chen, Z.H., Wang, X.D. and Zhou, T., "Theoretical Analysis and Experimental Research on Stability Behavior of Structural Steel Tube and Coupler Falsework with X-Bracing", Advanced Steel Construction, 2010a, Vol. 6, No. 4, pp. 949-962.

[5] Liu, H., Zhao, Q., Wang, X., Zhou, T., Wang, D., Liu, J. and Chen, Z., "Experimental and Analytical Studies on the Stability of Structural Steel Tube and Couple Scaffolds without X-bracing”, Engineering Structures, 2010b, Vol. 32, pp. 1003-1015. 
[6] Peng, J.L., Pan, A.D., Rosowsky, D.V., Chen, W.F., Yen, T. and Chan, S.L., "High Clearance Scaffold Systems during Construction - I. Structural Modelling and Modes of Failure", Engineering Structures, 1996a, Vol. 18, No. 3, pp. 247-257.

[7] Peng, J.L., Rosowsky, D.V., Pan, A.D., Chen, W.F., Chan, S.L. and Yen, T., "High Clearance Scaffold Systems during Construction - II. Structural Analysis and Development of Design Guidelines", Engineering Structures, 1996b, Vol. 18, No. 3, pp. 258-267.

[8] Peng, J.L., Pan, A.D.E., Chen, W.F., Yen, T. and Chan, S.L., "Structural Modeling and Analysis of Modular Falsework Systems", Journal of Structural Engineering, ASCE, 1997, Vol. 123, No. 9, pp. 1245-1251.

[9] Peng, J.L., Pan, A.D.E. and Chan, S.L., "Simplified Models for Analysis and Design of Modular Falsework", Journal of Constructional Steel Research, 1998, Vol. 48, No. 2/3, pp. 189-209.

[10] Peng, J.L., Pan, A.D.E. and Chen, W.F., "Approximate Analysis Method for Modular Tubular Falsework", Journal of Structural Engineering, ASCE, 2001, Vol. 127, No. 3, pp. 256-263.

[11] Peng, J.L., Chan, S.L. and Wu, C.L., "Effects of Geometrical Shape and Incremental Loads on Scaffold Systems", Journal of Constructional Steel Research, 2007, Volume 63, Issue 4, pp. 448-459.

[12] Peng, J.L., Wang, P.L., Huang, Y.H. and Tsai, T.C., "Experimental Studies of Load Capacities of Double-Layer Shoring Systems", Advanced Steel Construction, 2010, Vol. 6, No. 2, pp. 698-721.

[13] Peng, J.L., Yen, T., Kuo, C.C. and Chan, S.L., "Analytical and Experimental Bearing Capacities of System Scaffolds", Journal of Zhejiang University SCIENCE A, 2009, Vol. 10, No. 1, pp. 82-92.

[14] Weesner, L.B. and Jones, H.L., "Experimental and Analytical Capacity of Frame Scaffolding”, Engineering Structures, 2001, Vol. 23, No. 6, pp. 592-599.

[15] Yu, W.K., Chung, K.F. and Chan, S.L., "Structural Instability of Multi-storey Door-type Modular Steel Scaffolds", Engineering Structures, 2004, Vol. 26, pp. 867-881.

[16] Zhang, H., Chandrangsu, T. and Rasmussen, K.J.R., "Probabilistic Study of the Strength of Steel Scaffold Systems", Structural Safety, 2010, Vol. 32, pp. 393-401.

[17] Zhang, H., Rasmussen, K.J.R. and Ellingwood, B.R., "Reliability Assessment of Steel Scaffold Shoring Structure for Concrete Formwork", Engineering Structures, 2012, Vol. 36, pp. 81-89. 